Reinforced Flexural Elements for TEMP-STRESS Program

by

A. H. Marchertas*, J. M. Kennedy and P. A. Pfeiffer

June 1987

\title{
DISCLAIMER
}

This report was prepared as an account of work sponsored by an agency of the United States Government. Neither the United States Government nor any agency thereof, nor any of their employces, makes any warranty, express or implied, or assumes any legal liability or responsibility for the accuracy, complcteness, or usefulness of any information, apparatus, product, or process disclosed, or represents that its use would not infringe privately owned rights. Reference herein to any specilic commercial product, process, or service by trade name, trademark, manufacturer, or otherwise does not necessarily constitute or imply its endorsement, recommendation, or favoring by the United States Government or any agency thereof. The views and opinions of authors expressed herein do not necessarily state or reflect those of the United States Government or any agency thereof.

\author{
Reactor Analysis and Safety Division \\ ARGONNE NATIONAL LABORATORY \\ 9700 South Cass Avenue \\ Argonne, Illino is 60439
}

*Present address, Mechanical Engineering Department, Northern 111 inois University, Dekalb, Illinois 60115. 


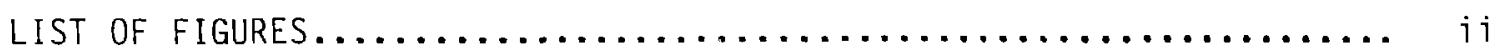

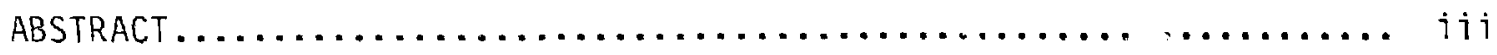

1. intRODUCTION..................................... 1

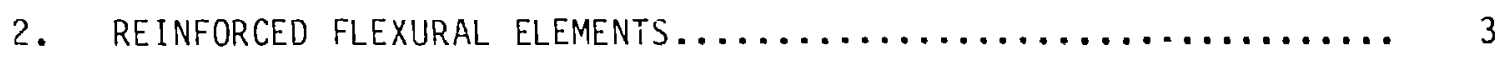

2.1 Reinforced Beam............................. 3

2.2 Reinforced Axisymmetric Shel $\ldots \ldots \ldots \ldots \ldots \ldots \ldots \ldots \ldots \ldots, 10$

3. TEMPORAL INTEGRATION ALGORITHM....................... 20

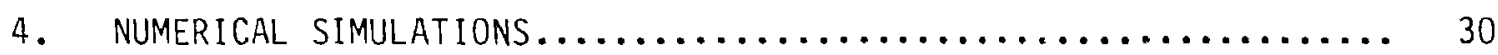

4.1 Simply Supported Reinforced Concrete Beam.............. 30

4.2 One-Sixth Scale Axisymmetric Reinforced Concrete

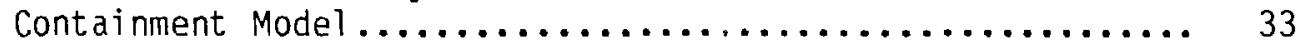

4.2.1 Static Internal Pressurization................. 37

4.2.2 Thermal Loading and Pressurization............... 42

4.2 .3 Dynamic Loading $. . \ldots \ldots \ldots \ldots \ldots \ldots \ldots \ldots \ldots \ldots \ldots, 43$

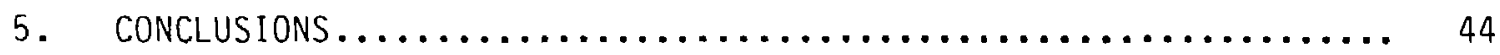

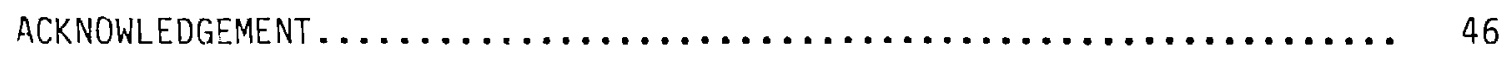

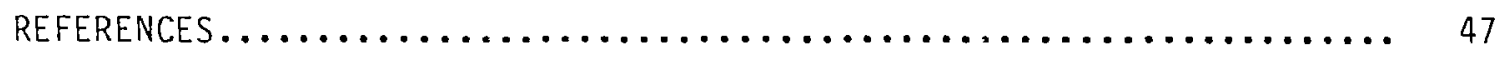


1. Beam Element Notation......................... 5

2. Shear Tie Reinforcement for Beam.................... 7

3. Axisymmetric Conical Shell Element.................... 11

4. Representation of Reinforcement in Concrete Axisymmetric Shell Element................................ 15

5. Seismic Reinforcement for Shell................... 16

6. Loading Method for Dynamic Relaxation.................. 25

7. Simply Supported Reinforced Concrete Beam................ 31

8. Load vs. Deflection for Beam Example.................. 32

9. One-sixth Scale Reinforced Concrete Containment............. 34

10. Discretization of Containment Model .................... 35

11. Deformation of Vessel at Impending Failure................ 39

12. Radial and Vertical Displacements of Liner at Cylinder Midheight................................ 40

13. Radial and Vertical Displacements of Liner at Vessel Springline. 
The implementation of reinforced flexural elements into the thermalmechanical finite element program TEMP-STRESS is described. With explicit temporal integration and dynamic relaxation capabilities in the program, the flexural elements provide an efficient method for the treatment of reinforced structures subjectecil to transient and static loads.

The capability of the computer program is illustrated by the solution of several examples: the simulation of a reinforced concrete beam; simulations of a reinforced concrece containment shell which is subjected to internal pressurization, thermal gradients through the walls, and transient pressure loads. The results of this analysis are relevant in the structural design/safety evaluations of typical reactor containment structures. 
1. INTRODUCTION

Public safety has been of foremost importance in the U. S. operation of nuclear reactors. The design of all nuclear reactors must possess appropriate containment to guard the public from possible exposure to harmful radiation. It is imperative in nuclear reactor design, therefore, to ascertain that in the event of a nuclear reactor accident, the radiation level to which the public is exposed would be safe.

It has been the coritention of Argonne National Laboratory (ANL) that safe structural containment can be provided by reinforced/prestressed concrete structures. It was also claimed that in case of a nuclear accident, ultimate failure of a concrete containment structure would be benign rather than catastrophic. Furthermore: nuclear containnient would not unly assure safety, but would also be economicãlly viable.

In view of the potential of concrete contairment, Argonne National Laboratory has launched a concentrated research effort into this area. First, analytical modeling of concrete containment began in 1976 and was prompted by the promise that prestressed concrete reactor vessels (PCRV's) would have very high energy absorbing capability as primary containment. This led to the development of the DYNAPCON program $[1,2,3]$. Using the DYNAPCON program, feasibility studies established satisfactory estimates of the typical containment energy absorbing capability [4] to withstand dynamic loads beyond what is currently expected in fast reactor designs.

The secondary containment, which might be subjected to accidental coolant spills and sprays, resulting in sodium fires and hydrogen deflagration, could also be handled by concrete-type structures. For this purpose the development of a different program, TEMP-STRESS $[5,6,7,8,9]$, which was to treat the 
thermal and mechanical effects, followed. This program incorporated the same features as DYNAPCON plus those needed for steady state and transient thermal problems. The introduction of dynamic relaxation in conjunction with explicit temporal integration enabled the program to be used for transient as we 11 as static loading. The basic architecture of the program followed the features of the STRAW computer program $(10,11,12,13)$.

Modifications of the TEMP-STRESS program are continuing with improvements aimed at increasing user convenience and efficiency of the numerical solution. The present paper describes the formulation of the reinforced flexural elements, which will enhance the versatility of the program. 


\section{REINFORCED FLEXURAL ELEMENTS}

The finite element program TEMP-STRESS uses explicit temporal integration coupled with dynamic relaxation. This combination facilitates the use of the program to highly nonlinear material problems, as characterized by concrete. It also enables the use of loads ranging from impulsive to static. For static problems, equilibrium of the solution is assured.

The modeling of reinforced concrete thus far has been handled by a quadrilateral continuum element with one point integration. Although this element is simple and quite efficient, its use for relative?y thin sections, like the containment shell, is very cumbersome. Therefore, the formulation of a reinforced flexural beam and shell element is a welcome addition to the element library. The use of this element in combination, with the continuum element, will cover a very wide range of applications in design/safety.

The flexural beam and shell elements are modified by the superposition of uniaxial reinforcement. The uniaxial reinforcement will be assumed to be embedded paralled to the respective neutral axis/surface of the element. The cross-sectional area, the normal distance of the reinforcement from the neutral axis/surface of the element and the stress-strain data of the reinforcement material will be assumed known.

\subsection{Reinforced Beam}

The parent beam element in TEMP-STRESS uses a corotational formulation similar to that described in Belytschko and Hsieh [14] with a velocity-strain instead of the stretch to measure deformation. Standard engineering beam theory, often known as Eular-Bernoulli beam theory, is used. This theory assumes that plane sections normal to the midline rema in plane and normal. 
According to the Euler-Bernoulli assumption, the velocity distribution for points normal to the beam axis is given by

$$
\hat{v}_{x}=\hat{x}-\hat{y} \frac{\partial \hat{v} y}{\partial \hat{x}}
$$

where the velocities $\hat{v}$ refer to the midline. The velocity-strain description is then given by

$$
\hat{n}_{x}=\frac{\partial \hat{v} x}{\partial \hat{x}}-\hat{y} \frac{\partial^{2} \hat{v}_{y}}{\partial \hat{x}^{2}}
$$

The velocity field for the element is decomposed into the rigid body motion plus the deformations. The rigid body motion consists of the translation and rotation and does not contribute to the strain of the beam and thus will be neglected. The deformation component of the velocity field is described in the axial direction by a linear expression in $\hat{x}$ and in the transverse direction by a cubic expression in $\hat{x}$. This can be represented as follows:

$$
\begin{aligned}
& \hat{v}_{x}=\left(\hat{v}_{x 2}-\hat{v}_{x 1}\right) \frac{\hat{x}}{l}+\hat{v}_{x 1} \\
& \hat{v}_{y}=\ell\left[\left(\frac{\hat{x}}{l}\right)^{3}-2\left(\frac{\hat{x}}{l}\right)^{2}+\frac{\hat{x}}{l}\right]\left(\dot{\phi}_{1}-\dot{\theta}\right)+\ell\left[\left(\frac{\hat{x}}{l}\right)^{3}-\left(\frac{\hat{x}}{l}\right)^{2}\right]\left(\dot{\phi}_{2}-\dot{\theta}\right)
\end{aligned}
$$

where $\dot{\phi}_{1}$ and $\dot{\phi}_{2}$ are the deformation components of the angular velocities of the nodes relative to the $\hat{x}$-axis and

$$
\dot{\theta}=\frac{1}{l}\left(\hat{v}_{y 2}-\hat{v}_{y 1}\right)
$$

is the angular velocity of the $\hat{x}$-axis shown in Fig. 1 . 

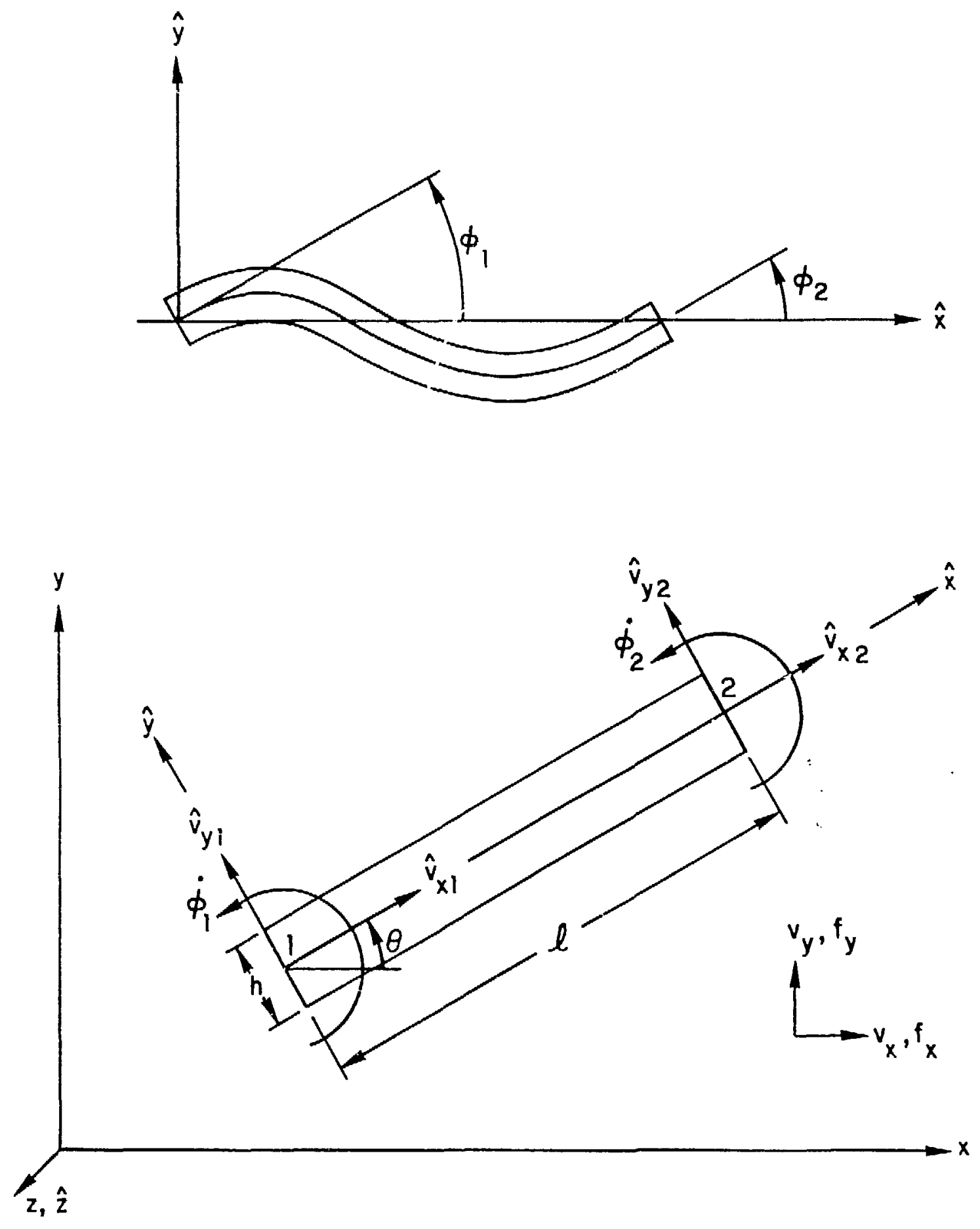

Figure 1. Beam Element Notation 
By performing the indicated differentiations in Eq. (2) on the velocity field components in Eq. (3), wo obtain the following velocity strain

$$
\hat{n}_{x}=|B|^{\top}\left\{\begin{array}{l}
\hat{v}_{x 2}-\dot{v}_{x 1} \\
\dot{\phi}_{1}-\dot{\theta} \\
\dot{\phi}_{2}-\dot{\theta}
\end{array}\right\}
$$

where

$$
[B]^{\top}=\frac{1}{\ell^{2}}[\ell \quad \hat{y}(4 \ell-6 \hat{x}) \quad \hat{y}(2 \ell-6 \hat{x})]
$$

becomes the transpose of the $[B]$ matrix for the beam element. The velocity strains are only required at the end nodes of the beam, which from Eq. (5), yield

$$
\begin{aligned}
& \hat{\eta}_{x}(0, \hat{y})=\frac{1}{\ell}\left(\hat{v}_{x 2}-\hat{v}_{x 1}+\hat{y}\left[4\left(\dot{\phi}_{1}-\dot{\theta}\right)+2\left(\dot{\phi}_{2}-\dot{\theta}\right)\right]\right) \\
& \hat{\eta}_{x}(\ell, \hat{y})=\frac{1}{2}\left(\hat{v}_{x 2}-\hat{v}_{x 1}-\hat{y}\left[2\left(\dot{\phi}_{1}-\dot{\theta}\right)+4\left(\dot{\phi}_{2}-\dot{\theta}\right)\right]\right)
\end{aligned}
$$

The velocity strains at the ends of the beam defined by Eq. (7) are used to derive the velocity strains in the reinforcing layers. Thus, with the distance $\hat{y}$ from the neutral axis specified for each reinforcing layer, the velocity strain of each layer is given by Eq. (7).

The reinforcement of the shear ties, as shown in Fig. 2, is also treated in this formulation. The neutral axis of the beam in Fig. 2 is used to relate the velocity strain in the ties to the axial velocity strain corresponding to the ends of the ties. The velocity strain in the ties, from geometrical considerations, becomes 


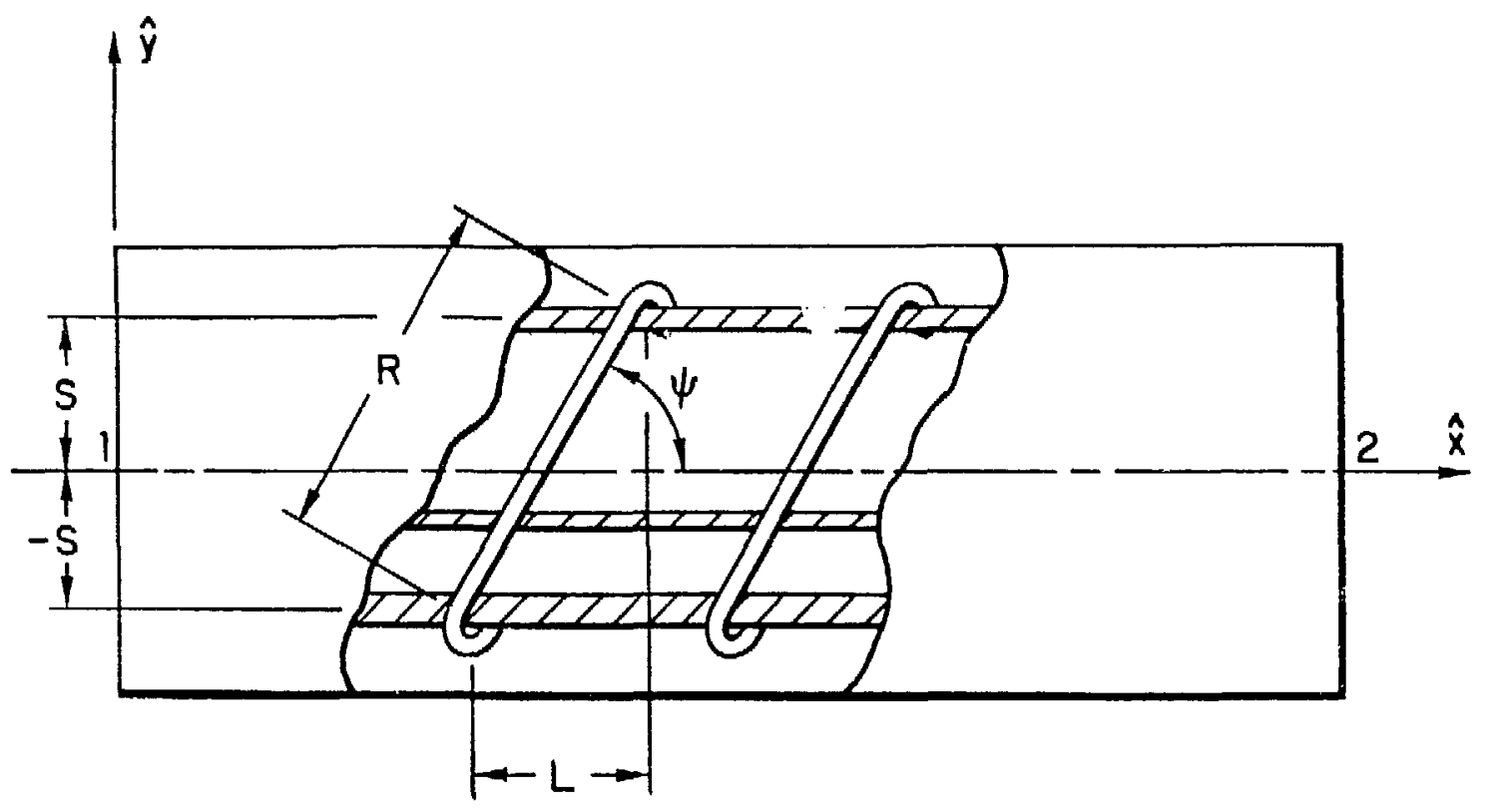

Figure 2. Shear Tie Reinforcement for Beam 


$$
\hat{n}_{t}=\frac{1}{8}\left[\hat{n}_{x}(0, s)+\hat{n}_{x}(l, s)\right]\left[4+\hat{n}_{x}(0, s)+\hat{n}_{x}(l, s)\right] \cos ^{2} \psi
$$

where $\psi i:$ the angle of inclination of the ties with respect to the $\hat{x}$-axis.

With the stress of the reinforcing layers calculated from the uniaxial stress-strain data, the contribution of axial force and moments at the ends of the beam element are determined. The contribution of the reinforcement is now added to that of the homogeneous beam. First, the internal forces of the constant width beam are given as

$$
\left\{\begin{array}{c}
\hat{f}_{x 2} \\
m_{1} \\
m_{2}
\end{array}\right\}=w \int_{0}^{2} \int_{-\frac{h}{2}}^{\frac{h}{2}}[B]^{T^{n}} \sigma_{x}(\hat{x}, \hat{y}) d \hat{y} d \hat{x}
$$

where $w$ is the width and $\hat{\sigma}_{x}(\hat{x}, \hat{y})$ is the respective stress in the layer. The contribution to the force and moments from all the layers of reinforcement parallel to the neutral axis are given as the sum as follows:

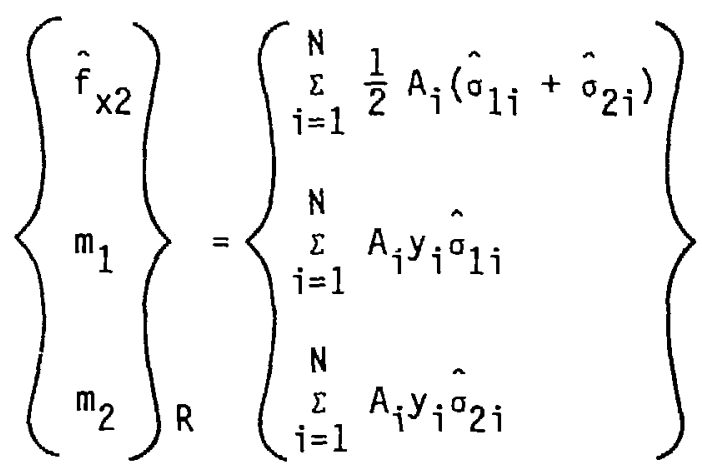

where $N$ is the number of reinforcing layers through the element thickness, $A_{j}$ and $y_{j}$ pertain to the cross-sectional area and distance from the neutral axis of the $i$-th reinforcing layer, respectively, and $\hat{\sigma}_{1 j}$ and $\hat{\sigma}_{2 i}$ are the rein- 
forcement stresses at $\hat{x}=0$ and $\hat{x}=\ell$, respectively. For the ties, which are inclined at angle $\psi$ with respect to the neutral axis of the beam, the reinforcement contribution is

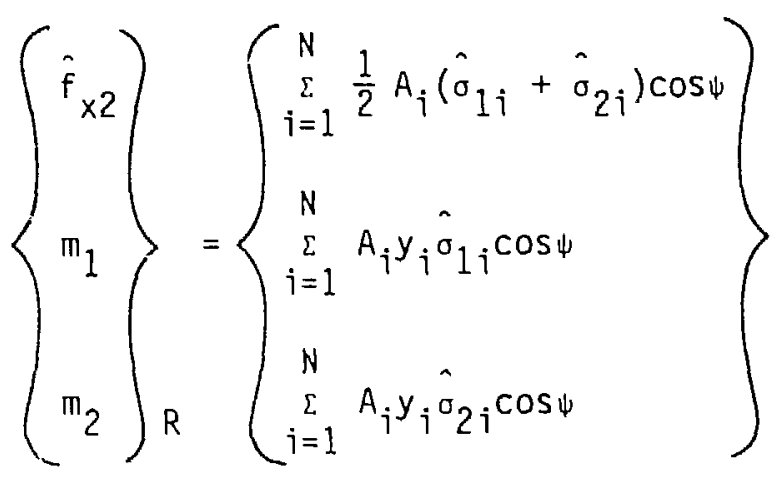

Thus, the tota 1 internal force and moment of the reinforced beam becomes

$$
\left\{\begin{array}{l}
\hat{f}_{x 2} \\
m_{1} \\
m_{2}
\end{array}\right\}=\left\{\begin{array}{l}
\hat{f}_{x 2} \\
m_{1} \\
m_{2}
\end{array}\right\}_{B}+\left\{\begin{array}{l}
\hat{f}_{x 2} \\
m_{1} \\
m_{2}
\end{array}\right\}_{R}
$$

From equilibrium considerations of the beam it is observed that

$$
\begin{aligned}
& \hat{f}_{x 1}=-\hat{f}_{x 2} \\
& \hat{f}_{y 2}=-\frac{1}{2}\left(m_{1}+\dot{m}_{2}\right) \\
& \hat{f}_{y 1}=-\hat{f}_{y 2}
\end{aligned}
$$

For each node $n$, the individual components of internal force are then resolved into the respective components of global coordinates by the following transformation 


$$
\left\{\begin{array}{l}
f_{x n} \\
f_{y n}
\end{array}\right\}=\left[\begin{array}{rr}
\cos \theta & -\sin \theta \\
\sin \theta & \cos \theta
\end{array}\right]\left\{\begin{array}{l}
\hat{f}_{x n} \\
\hat{f}_{y n}
\end{array}\right\}
$$

The internal forces of Eq. (14) and the moments $m_{1}$ and $m_{2}$ represent the element contribution to the nodal forces by the beam element.

\subsection{Reinforced Axisyminetric Shell}

A straight conical sheli element with velocity strain is used in the TEMP-STRESS program. This is a modified element originally presented by Belytschko and Hsieh [15] and is shown in Fig. 3. The forces and moments of this shell are computed at two Gaussian integration stations along the length and an arbitrary number of Gaussian integration stations across the depth of the element. This element is assumed to be of constant thickness and employs the Kirchhoff type shell theory, where normals of the middle surface remain straight and normal, and the transverse shear is neglected. The formulation is based on one radian sector.

In the shell a plane stress condition exists with meridional stress $\hat{\sigma}_{m}$ and circumferential (hoop) stress $\sigma_{\theta}$, respectively. The corresponding velocity strains from the Kirchhoff assumption are given as

$$
\begin{aligned}
& \hat{n}_{x}=\frac{\partial \hat{v}_{x}}{\partial \hat{x}}-\hat{y} \frac{\partial^{2} \hat{v}_{y}}{\partial \hat{x}^{2}} \\
& \eta_{\theta}=\frac{v_{r}}{r}-\hat{y} \frac{\cos \alpha}{r} \frac{\partial \hat{v}_{x}}{\partial \hat{x}}
\end{aligned}
$$




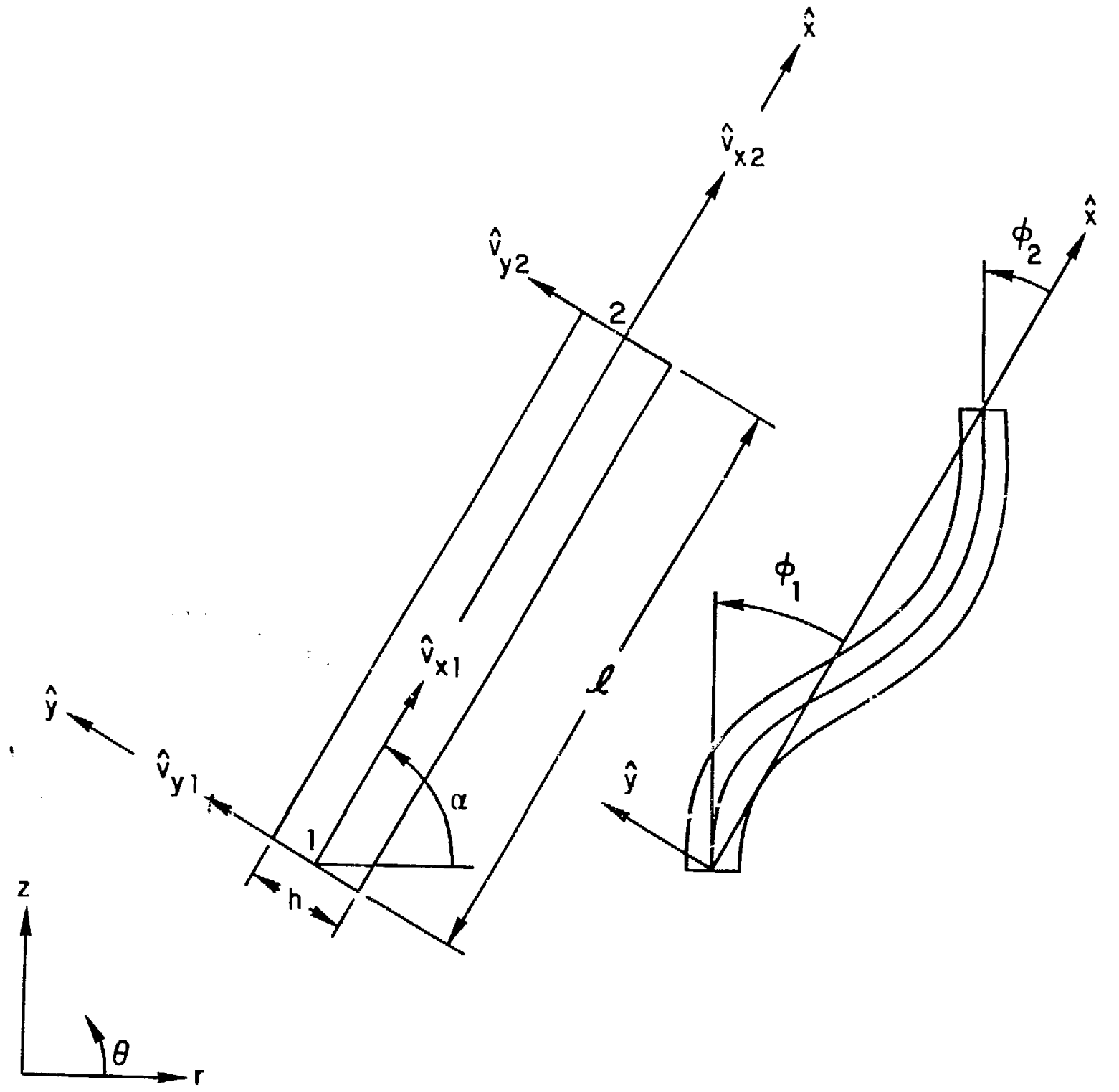

Figure 3. Axisymmetric Conical Shell Element 
Here the first of Eq. (15) pertains to the meridional midline velocity strain, which is equivalent to Eq. (2). The second equation refers to the circumferential velocity strain. The velocity field of the shell element is assumed to be linear in the meridional and cubic in the transverse (hoop) direction. When the appropriate shape functions are prescribed and the indicated differentiation of Eq. (15) performed, we obtain

$$
\left\{\begin{array}{l}
n_{x} \\
n_{\theta}
\end{array}\right\}=\left(\left[B^{a}\right]+\hat{y}\left[B^{b}\right]\right)\left\{\begin{array}{c}
v_{r 1} \\
v_{z 1} \\
\dot{\phi}_{1} \\
v_{r 2} \\
v_{z 2} \\
\dot{\phi}_{2}
\end{array}\right\}
$$

where

$$
\left[B^{a}\right]^{\top}=\left[\begin{array}{ll}
-1 / \hat{\imath} & c(1-\xi) / 2 r \\
0 & -s\left(\xi^{3}-3 \xi+2\right) / 4 r \\
0 & -s l\left(\xi^{3}-\xi^{2}-\xi+1\right) / 8 r \\
1 / \ell & c(1+\xi) / 2 r \\
0 & -s\left(-\xi^{3}+3 \xi+2\right) / 4 r \\
0 & -s l\left(\xi^{3}+\xi^{2}-\xi-1\right) / 8 r
\end{array}\right]
$$




$$
\left[B^{b}\right]^{\top}=\left[\begin{array}{ll}
0 & 0 \\
6 \xi / l^{2} & 3 c\left(\xi^{2}-1\right) / 2 \ell r \\
(3 \xi-1) / l & c\left(3 \xi^{2}-2 \xi-1\right) / 4 r \\
0 & 0 \\
-6 \xi / l^{2} & -3 c\left(\xi^{2}-1\right) / 2 \ell r \\
(3 \xi+1) / \ell & c\left(3 \xi^{2}+2 \xi-1\right) / 4 r
\end{array}\right]
$$

with

$$
\begin{aligned}
& \xi=2 \hat{x} / \ell-1 \\
& c=\left(r_{2}-r_{1}\right) / \ell \\
& s=\left(z_{2}-z_{1}\right) / \ell \\
& \ell=\left[\left(r_{2}-r_{1}\right)^{2}+\left(z_{2}-z_{1}\right)^{2}\right]^{1 / 2} \\
& r=\left[(1-\xi) r_{1}+(1+\xi) r_{2}\right] / 2
\end{aligned}
$$

The velocity strains defined by Eq. (16) are utilized in the definition of the velocity strains of the reinforcement. Velocity strains of reinforcement are evaluated at the ends of the element, at locations $\hat{x}=0$ and $\hat{x}=\ell$, which correspond to the position of the nodes. The values of the [B] matrices at $\hat{x}=0$ are 


$$
\left|B^{a}\right|^{\top}=\left[\begin{array}{cc}
-1 / \ell & c / r_{1} \\
0 & -s / r_{1} \\
0 & 0 \\
1 / \ell & 0 \\
0 & 0 \\
0 & 0
\end{array}\right] \quad\left[\left.B^{b}\right|^{\top}=\left[\begin{array}{cc}
0 & 0 \\
-6 / e^{2} & 0 \\
-4 / \ell & c / r_{1} \\
0 & 0 \\
6 / e^{2} & 0 \\
-2 / l & 0
\end{array}\right]\right.
$$

and those at $\hat{x}=\ell$ become

$$
\left[B^{a}\right]^{\top}=\left[\begin{array}{cc}
-1 / \ell & 0 \\
0 & 0 \\
0 & 0 \\
1 / \ell & c / r_{2} \\
0 & -s / r_{2} \\
0 & 0
\end{array}\right] \quad\left[B^{b}\right]^{\top}=\left[\begin{array}{cc}
0 & 0 \\
6 / e^{2} & 0 \\
2 / \ell & 0 \\
0 & 0 \\
-c / l^{2} & 0 \\
4 / l & c / r_{2}
\end{array}\right]
$$

The axisymmetric shell element is reinforced by uniaxial members as shown in Fig. 4. The treatment of meridional reinforcement in the shell element is identical to that of the axial reinforcement of the beam. Hoop reinforcement is handled similar to ring elements located at the ends (nodal points) of shell elements. The radius of this hoop reinforcement is specified by the neutral surface of the element and the distance of this reinforcement from the neutral surface.

Reinforcement, which spirals helically in the shell interior is shown in Fig. 5. This type of reinforcement is sumetimes referred to as seismic reinforcement. The helically wound reinforcement is referenced with respect to the axis of the shell by an angular coordinate $\phi$; when $\phi=0$ or $\phi=90^{\circ}$ the uniaxial reinforcement pertains to purely meridional and hoop directions, 


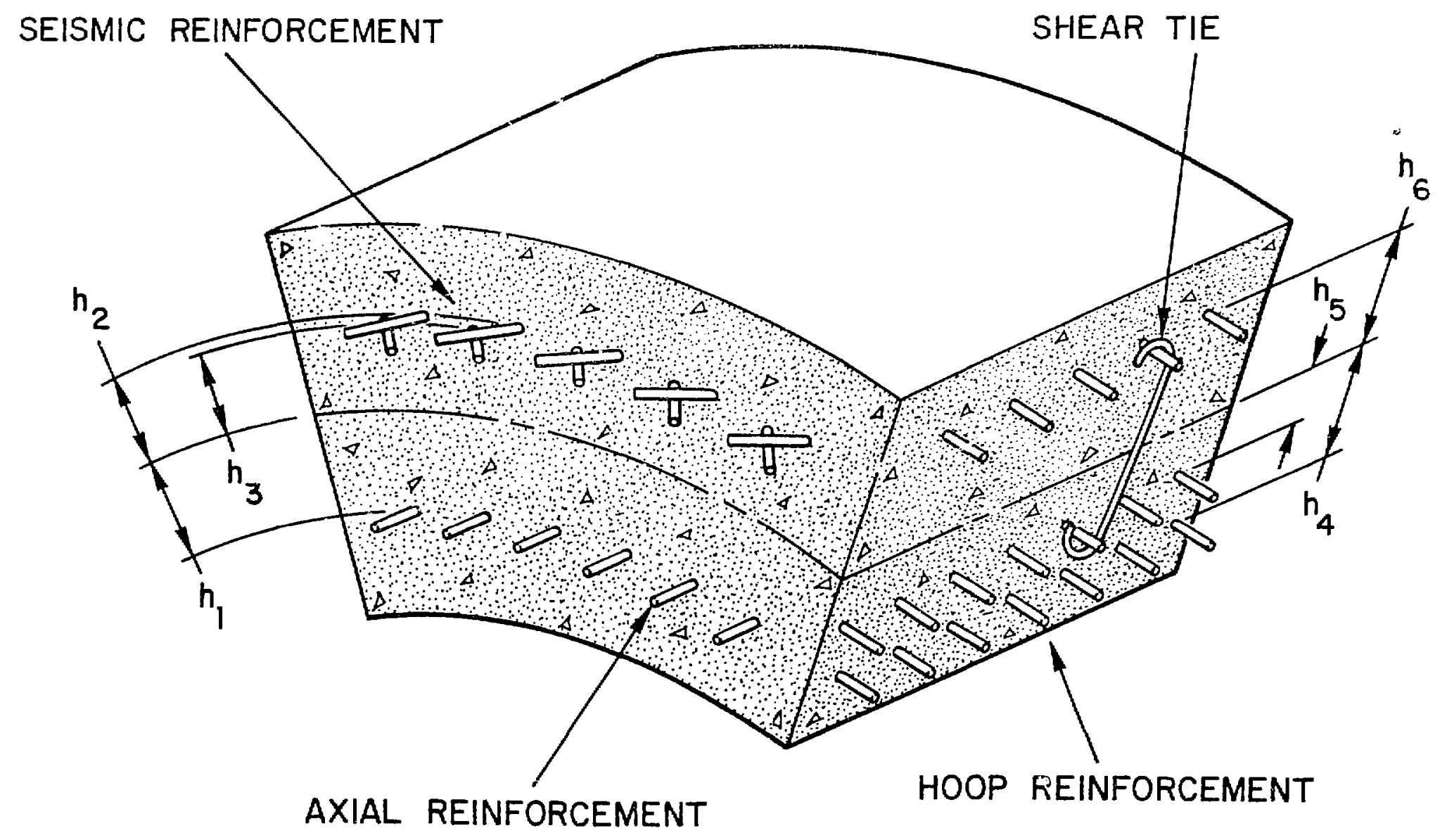

Figure 4. Representation of Reinforcement in Concrete Axisymmetric Shell Element 


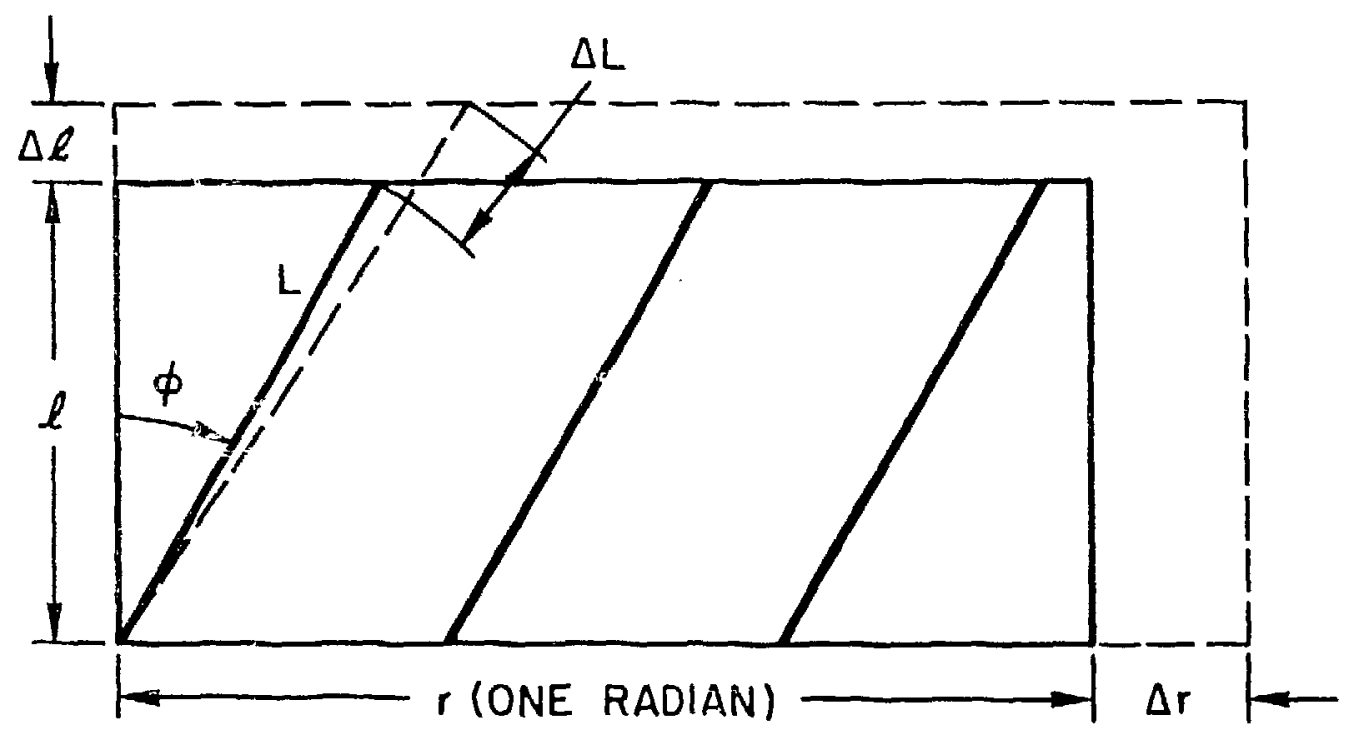

Figure 5. Seismic Reinforcement for She11 
respectively. For values between $0^{\circ}$ and $90^{\circ}$ the helical reinforcement is resolved into components of meridional and hoop directions.

The velocity strain of the helical reinforcement shown in Fig. 5 is expressed in terms of the meridional and hoop velocity strain, $\hat{n}_{x}$ and $\eta_{\theta}$, respectively. For the reinforcement shown, the corresponding velocity strain is given as

$$
\hat{n}_{\phi}=\frac{1}{2}\left[\hat{n}_{x}\left(2+\hat{n}_{x}\right) \cos ^{2} \phi+n_{\theta}\left(2+n_{\theta}\right) \sin ^{2} \phi\right]
$$

The nodal internal forces of the flexural shell element are obtained by integrating the stresses in the layers of the beam thickness $h$ and along the meridional length $\ell$. This results in

$$
\left\{\begin{array}{l}
\hat{f}_{x 1} \\
\hat{f}_{y 1} \\
m_{1} \\
\hat{f}_{x 2} \\
\hat{f}_{y 2} \\
m_{2}
\end{array}\right\}=\int_{0}^{e} \int_{s}^{\frac{h}{2}}\left(\left|B^{a}\right|+\hat{y}\left[B^{b} \mid\right)^{r}\left\{\begin{array}{c}
\hat{\sigma}_{x} \\
\sigma_{\theta}
\end{array}\right\} r d \hat{y} d \hat{x}\right.
$$

where we note that $\hat{f}_{y 1}=-\hat{f}_{y 2}$ for equilibril!in in the $\hat{y}$-direction. The contribution of the reinforcement members can be represented in the form of summation of all the reinforcement layers through the element thickness. Thus, for reinforcement layers in the plane of the shell, we have 
$-18$

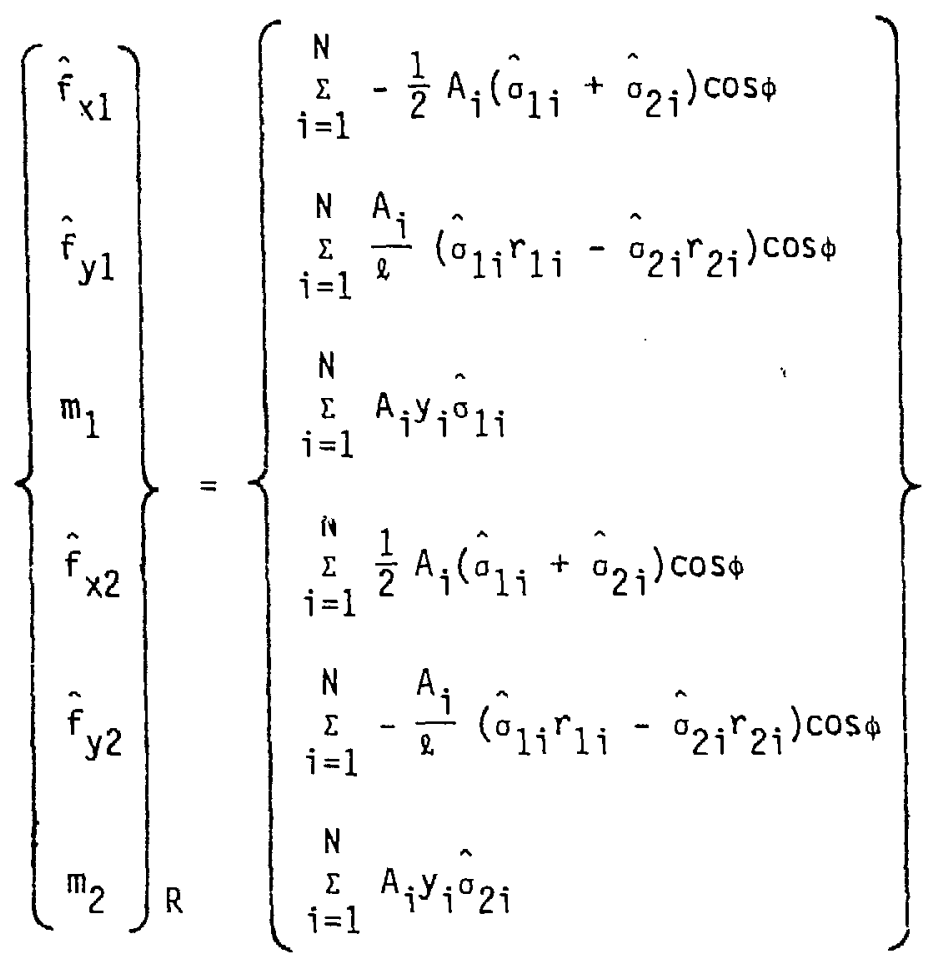

where $\mathrm{N}$ represents the total number of reinforcing layers. For the internal force contribution stemming from the ties, we have

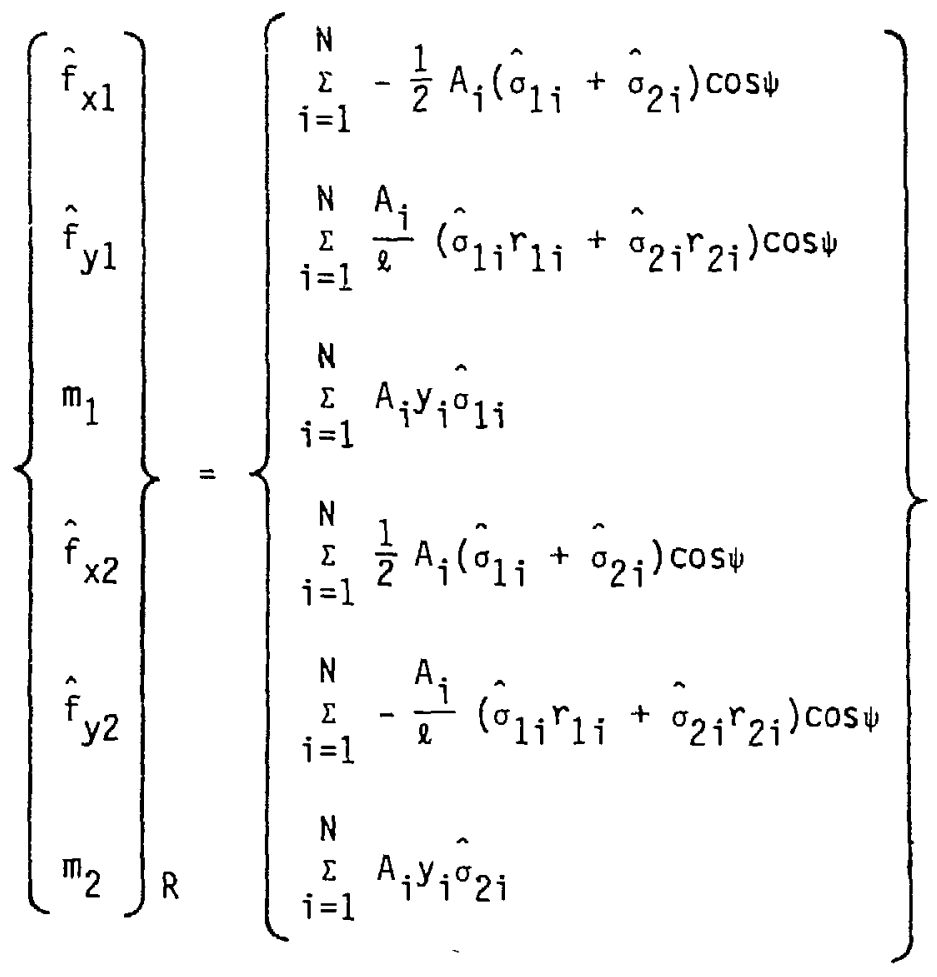


where $\psi$ is the angle of inclination of the ties with respect to the $\hat{x}$-axis shown in Fig. 2. Consequently, the force vector of the reinforced shell element becomes

$$
\left\{\begin{array}{c}
\hat{f}_{x 1} \\
\hat{f}_{y 1} \\
m_{1} \\
\hat{f}_{x 2} \\
\hat{f}_{y 2} \\
m_{2}
\end{array}\right\}=\left\{\begin{array}{c}
\hat{f}_{x 1} \\
\hat{f}_{y 1} \\
m_{1} \\
\hat{f}_{x 2} \\
\hat{f}_{y 2} \\
m_{2}
\end{array}\right\}_{B}+\left\{\begin{array}{c}
\hat{f}_{x 1} \\
\hat{f}_{y 1} \\
m_{1} \\
\hat{f}_{x 2} \\
\hat{f}_{y 2} \\
m_{2}
\end{array}\right\}
$$

For each node $n$ the local components of internal forces can be transformed to the force components in global coordinates as follows:

$$
\left\{\begin{array}{c}
f_{x n} \\
f_{y n}
\end{array}\right\}=\left[\begin{array}{cc}
\cos \theta & -\sin \theta \\
\sin \theta & \cos \theta
\end{array}\right]\left\{\begin{array}{c}
\hat{f}_{x n} \\
\hat{f}_{y n}
\end{array}\right\}+\left\{\begin{array}{cc}
\sum_{i=1}^{N} \frac{1}{2} A_{i}{ }^{c} n i & \sin \phi \\
0
\end{array}\right\}
$$

where the right-hand contribution stems from the reinforcement of the element. Note that for shear ties the angle $\phi$ of Eq. (27) becomes $\psi$. The internal forces of Eq. (27) and the meridional moments $m_{1}$ and $m_{2}$ represent the reinforced shell element contribution to the two end nodes. 


\section{TEMPORAL INTEGRATION ALGORITHM}

The non-linear effects encountered in the modeling of concrete can in principle be treated in numerous ways, such as by the use of incrementaliterative implicit procedures as well as by explicit integration. The explicit time integration scheme has been adopted in the TEMP-STRESS program for stress analysis of concrete under variable temperatures. This has been pirimarily dictated by the highly nonlinear concrete behavior and the relative ease of accounting for nonlinearity in this type of algorithm. Although explicit time integration has been previously used for transient problems, it was found also very convenient for static problems in conjunction with the dynamic relaxation technique. Thus, the procedure of determining the temperature field in the structure, which would be an integral part of a computer program designed for thermal stress analysis, should also involve explicit integration. Since the available heat conduction algorithms were based on iterative-type procedures, the development of an explicit technique was necessary [16].

The thermo-mechanical algorithm incorporated in the TEMP-STRESS program solves the following equations

$$
\begin{aligned}
& {[C]\{\dot{T}\}=\left\{H^{e x t}\right\}-\left\{H^{i n t}\right\}} \\
& {[M]\{\ddot{d}\}=\left\{F^{e x t}\right\}-\left\{F^{i n t}\right\}-\left\{F^{\text {damp }}\right\}+\left\{F^{g r a v}\right\}}
\end{aligned}
$$

where [C] is the lumped capacitance matrix, $[M]$ is the lumped mass matrix, $[T]$ is the column matrix of nodal temperatures, $[d]$ is the column matrix of nodal displacements, and the superimposed dot indicates time derivatives. It is noted here that for uniform capacitance through the element we have $[\mathrm{C}]=$ 
$\mathrm{C}[\mathrm{M}]$, where $\mathrm{c}$ is the specific heat. The external mechanical loads $\left\{\mathrm{F}^{\mathrm{ext}}\right.$ \} and those due to thermal effects $\left\{H^{\text {ext }}\right\}$ are usually handled by computer programs through boundary nodes. Thus, they would be taken care of by the computer program and no elaboration regarding external loading needs to be done at this point. The gravity loads $\left\{\mathrm{F}^{\text {grav }}\right\}$ are internally calculated in the program. The internal fcrces, however, are element-dependent and may be expressed as follows

$$
\begin{aligned}
& \left\{H^{\text {int }}\right\}=k \int_{V}[B]^{\top}[B] d V\{T\} \\
& \left\{F^{i n t}\right\}=\int_{V}[B]^{\top}\{a\} d V
\end{aligned}
$$

where $k$ is the thermal conductivity, $V$ is the volume of the element arid $\{0$ \} is the element stress matrix. The first derivatives of temperature $T$ can be written in matrix form as

$$
\left\{\begin{array}{l}
\frac{\partial T}{\partial r} \\
\frac{\partial T}{\partial Z}
\end{array}\right\}=[B][T\}
$$

defining the $[B]$ matrix. The same matrix also relates the velocity strain $\{n\}$ of the element to the nodal velocities $\{\dot{d}\}$ as

$$
\{\eta\}=[B]\{\dot{d}\}
$$

The damping force was introduced into the equation of motion to facilitate the dynamic relaxation. The form used is given by 


$$
\left\{F^{\text {damp }}\right\}=\left(\alpha_{1}[K]+\alpha_{2}(M]\right)\{\dot{d}\}
$$

where $[K]$ is the stiffness matrix and $[M]$ is the mass matrix. Thus, the first term of Eq. (34) pertains to the stiffness-proportional damping and the second term refers to mass-proportional damping. The individual $\alpha$ 's may be expressed as

$$
\begin{aligned}
& \alpha_{1}=\frac{2\left(\omega_{\max } \beta_{1}-\omega_{\min }{ }_{2}\right)}{2} \\
& \omega_{\max }^{2}-\omega_{\min } \\
& \alpha_{2}=\frac{2 \omega_{\max } \omega_{\min }\left(\omega_{\max }{ }^{\beta_{2}}-\omega_{\min ^{\beta} 1}\right)}{\omega_{\max }^{2}-\omega_{\min }^{2}}
\end{aligned}
$$

where $\beta_{1}$ and $\beta_{2}$ are the input damping ratios for the highest and lowest mesh frequency, respectively, and $\omega_{\max }$ and $\omega_{\min }$ are the maximum and minimum circuiar frequencies of the mesh, respectively. The stiffness matrix of Eq. (34) is approximated by the diagonal matrix, $[K]$, in which the terms are approximate "nodal stiffnesses" during the time increment $t$. The "nodal stiffness" for the $j$-th degree-of-freedom, $k_{j}$, is taken to be

$$
K_{j}=\left|\Delta F_{j}^{i n t} / \Delta d_{j}\right|
$$

The mass matrix $[M]$ in Eq. (34) is also approximated by a nodal mass matrix [M]. The minimum circular frequency is computed from an approximate Rayleigh quotient [17], and the maximum circular frequency is related to the critical timestep for the mesh as follows 


$$
\begin{aligned}
& \omega_{\min }=\sqrt{\sum_{I=1}^{N} k_{I} d_{I}^{2} / \sum_{I=1}^{N} M_{I} d_{I}^{2}} \\
& \omega_{\max } \simeq \frac{2}{\Delta t}{ }_{c r}
\end{aligned}
$$

where $N$ is the total number of degrees of freedom and $\Delta t_{c r}$ is the critical time step of the mesh. For the present work, only mass-proportional damping is considered $\left(\alpha_{1}=0\right)$. Hence, the damping force matrix can be expressed as follows:

$$
\left\{F^{\text {damp }}\right\}=2 \beta_{2}{ }^{\omega} \min [M]\{\dot{d}\}
$$

In order to take advantage of the explicit formulation we use the following difference form for Eqs. (28) and (29):

$$
\begin{aligned}
& \left.c[M]\{T\}^{i}=c \mid M\right]\{T\}^{i-1}+\Delta t\left(\left\{H^{e x t}\right\}^{i}-\left\{H^{i n t}\right\}^{i}\right) \\
& |M|\{d\}^{i}=\left\{F^{e x t}\right\}^{i}-\left\{F^{i n t}\right\}^{i}+\left\{F^{g r a v}\right\}^{i}-2 B_{2} 2_{\min }[M]\{d\}^{i}
\end{aligned}
$$

where

$$
\{\dot{\mathrm{d}}\}^{i}=\frac{1}{2 \Delta t}\left(\{\mathrm{~d}\}^{i+1}-\{d\}^{i-1}\right)=\{\dot{d}\}^{i-1 / 2}+\frac{\Delta t}{2}\{\ddot{d}\}^{i}
$$

Hence, upon substitution we get

$$
\{T\}^{i}=\{T\}^{i-1}+\frac{[M]^{-1}}{c} \Delta t\left(\left\{H^{\text {ext }}\right\}^{i}-\left\{H^{i n t}\right\}^{i}\right)
$$




$$
\begin{aligned}
\{\ddot{d}\}^{i} & =\frac{[M]^{-1}}{1+\Delta B_{2}{ }_{2} \min }\left(\left[F^{\text {ext }}\right\}^{i}-\left\{F^{i n t}\right\}^{i}+\left\{F^{g r a v}\right\}^{i}\right. \\
& \left.-2 B_{2} 2_{\min }[M]\{\dot{d}\}^{i-1 / 2}\right)
\end{aligned}
$$

The velocities and displacements are approximated by the central difference equations as follows:

$$
\begin{aligned}
& \{\dot{d}\}^{i+1 / 2}=\{\dot{d}\}^{i-1 / 2}+\Delta t\{\dot{d}\}^{i} \\
& \{d\}^{i+1}=\{d\}^{i}+\Delta t\{\dot{d}\}^{i+1 / 2}
\end{aligned}
$$

When the explicit integration technique is applied to solve a transient problem, the time parameter used there pertains to the actual time of the physical process. In quasi-steady state and steady state problems the time parameter in explicit integration loses its original meaning; it no longer means real time, but rather an integration parameter proportional to time. For purely statics problems this time parameter becomes solely an integration parameter.

In the computer code the externai loads $\left\{\mathrm{F}^{\text {ext }}\right\}$ are prescribed by input. To facilitate dynamic relaxation, this loading is applied incrementally, i.e., in load steps of specified magnitude. Hence, dynamic relaxation for each of the load increments permits readjustment of the structure while approaching statis equilibrium asymptotically, as shown in Fig. 6. Static equilibrium is attained at definite points as indicated in Fig. 6 .

Equilibrium of the system is established by the imposition of two criteria. One of the criteria is equivalent to the comparison of internal forces with the external forces at the same interation step. The other 

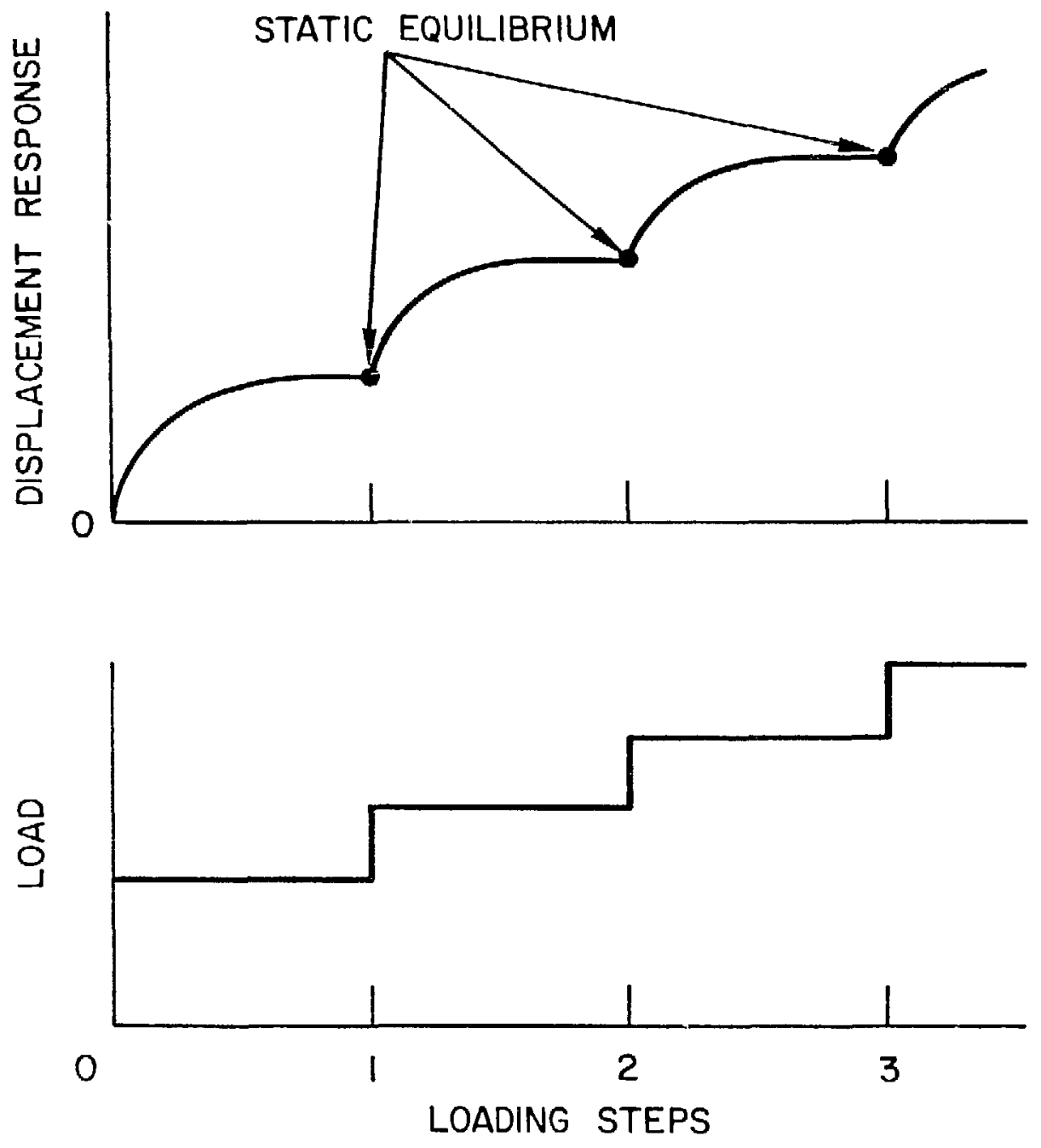

Figure 6. Loading Method for Dynamic Relaxation 
criterion is tantamount to the comparison of displacements at successive iteration steps. In mathematical terms these criteria can be expressed as follows:

$$
100 \sqrt{\sum_{I=1}^{N}\left(F_{I}^{\text {ext }}-F_{I}^{i n t}\right)^{2} / \sum_{I=1}^{N}\left(F_{I}^{\text {ext }}\right)^{2}} \leq \varepsilon_{F}
$$

and

$$
100\left(\sum_{I=1}^{N} \dot{d}_{I} \Delta t / \sum_{I=1}^{N} d_{I}\right) \leq \varepsilon_{d}
$$

where $\varepsilon_{F}$ and $\varepsilon_{d}$ are the force and displacement tolerances in percent, respectively.

The explicit computations programmed in the TEMP-STRESS program are performed in the following sequence: 


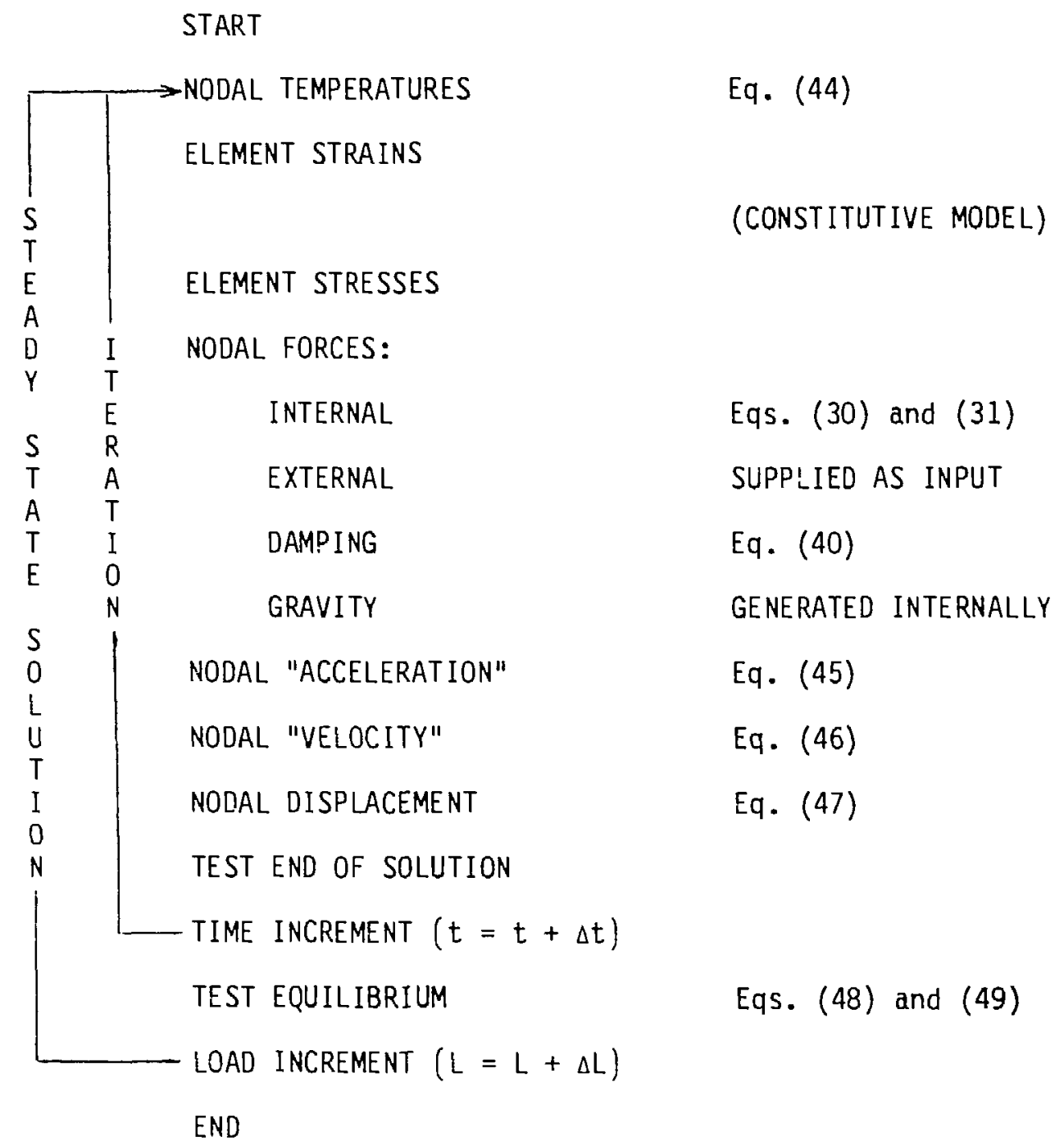


The calculations are made repeatedly in time steps continually updating the value of the previous time step. For transient solutions the increment in time is controlled by a stability criterion depending on the discretization of the model and material properties.

The stability limit for structural calculations is given by the critical time step

$$
\Delta t \leq \frac{2}{\omega_{\max }}\left(\sqrt{1+\beta_{1}^{2}}-\beta_{1}\right)
$$

For thermal solutions, the critical time step [16] is

$$
\Delta t=\frac{\rho C l}{2 k}
$$

where $\ell$ is the shortest distance between nodes, $\rho$ is the mass density, $c$ is specific heat, and $k$ is the conductivity. In beam or shell elements, the maximum frequency for translation is

$$
w_{\max }^{2}=\frac{4 c^{2}}{e^{2}}
$$

and the rotary inertia for rotation is

$$
\omega_{\max }^{2} \simeq \frac{16 c^{2} h^{2}}{e^{4}}
$$

where $\ell$ is tha distance between the nodes, $c$ is the elastic wavespeed, and $h$ is the height of the bean or shell. The square of the elastic wavespeed for particular conditions is defined as 


$$
\begin{aligned}
& c^{2}=\frac{E}{D} \quad(\text { uniaxial piane stress) } \\
& c^{2}=\frac{E}{\rho\left(1-v^{2}\right)}\left(\begin{array}{l}
\text { uniaxial plane strain } \\
\text { or } \\
\text { biaxial plane stress }
\end{array}\right)
\end{aligned}
$$

where $E$ is Young's modulus, $\rho$ is mass density, and $v$ is Poisson's ratio. Note that when determining the maximum frequency for the structure, the largest value from Eq. (52) or (53) must be used.

From Eqs. (50), (52), and (53), it can be seen that an inefficient time step (too small) may result if there are large differences in beam (or shell) lengths or a large difference between translational and rotational frequencies which, for static solutions, will cause excessive computation time. This inefficiency may be overcome by using a concept of mass-adjustment. The principal feature of this method is to use a constant $\Delta t$ (usually $=1.0$ for convenience). This is done by adjusting the mass density, $\rho$, for both translational and rotational frequencies, utilizing the stability time limit relationship given in Eq. (50). From experience, by utilizing the adjusted mass scheme, a considerable saving in computational time may result, depending on the structure and discretization. 


\section{NUMERICAL SIMULATIONS}

\subsection{Simply Supported Reinforced Concrete Beam}

The accuracy and validity of the reinforced beam element is investigated in comparison with test results of a reinforced concrete slender beam. The test data pertains to a simply supported concrete beam reinforced by four steel bars, as shown in Fig. 7. The beam is subjected to a gradually increasing mid-span load.

The analytical model takes advantage of the symmetry of the test specimen and models one-half of the beam. It represents the beam from the center to the support. Four reinforced elements of equal size are utilized. Five equal integration layers are used through the depth of the beam and two integration layers along the length (at the end nodes). The four concrete elements are reinforced with two rows of steel bars. Properties of the concrete are: Young's modulus $=3100 \mathrm{ksi}(21460 \mathrm{MPa})$, Poisson's ratio $=0.2$, compression strength $=3500$ psi $(24.1 \mathrm{MPa})$ and tensile strength $=333 \mathrm{psi}(2.3 \mathrm{MPa})$. The maximum strain in tension (where the stress is zero) when softening is used, was set at 0.0007 in./in. Properties of the rebar are: Young's modulus $=$ $27778 \mathrm{ksi}(192000 \mathrm{MPa})$, Poisson's ratio $=0.3$, yield stress $=60 \mathrm{ksi}(414 \mathrm{MPa})$ and ultimate stress $=144 \mathrm{ksi}(993 \mathrm{MPa})$ at $6 \%$ strain. The analytical models include two variations, one with and the other without tensile softening of the stress-strain curve.

A comparison of test load-deflection and the analytical prediction is shown in Fig. 8. The analytical data with tensile softening corresponds closer to the test results during initial cracking. The deviations of the analytical results from the test data, as loading increases, are attributed to 


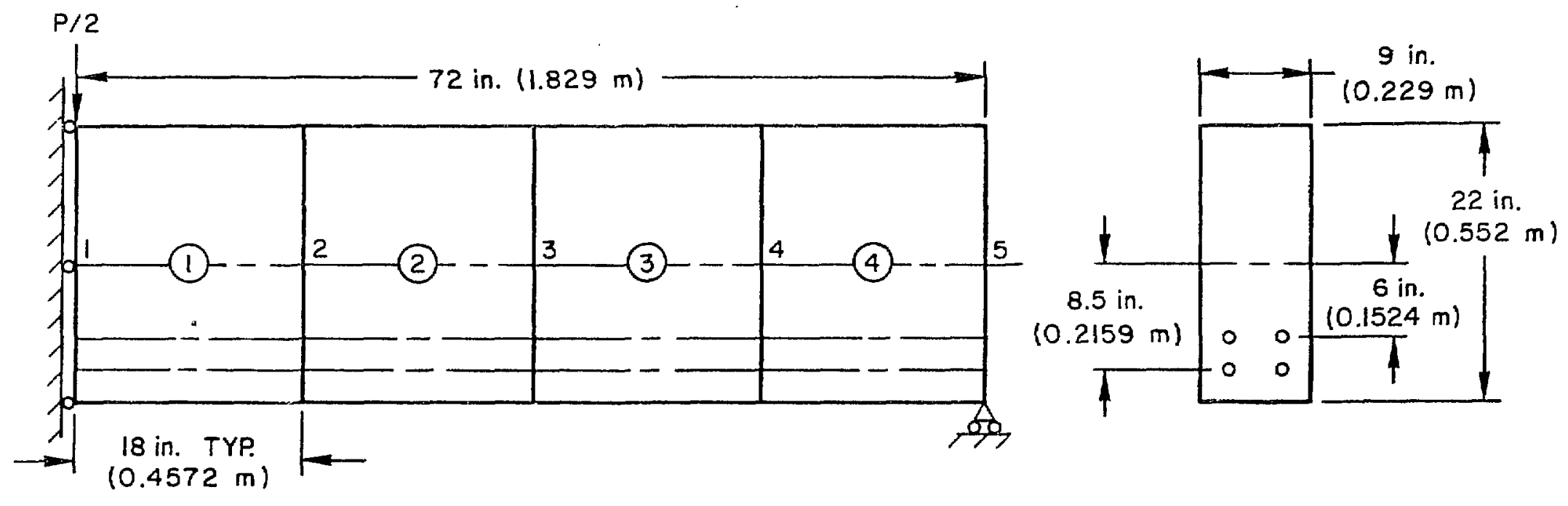

Figure 7. Simply Supported Reinforced Concrete Beam 


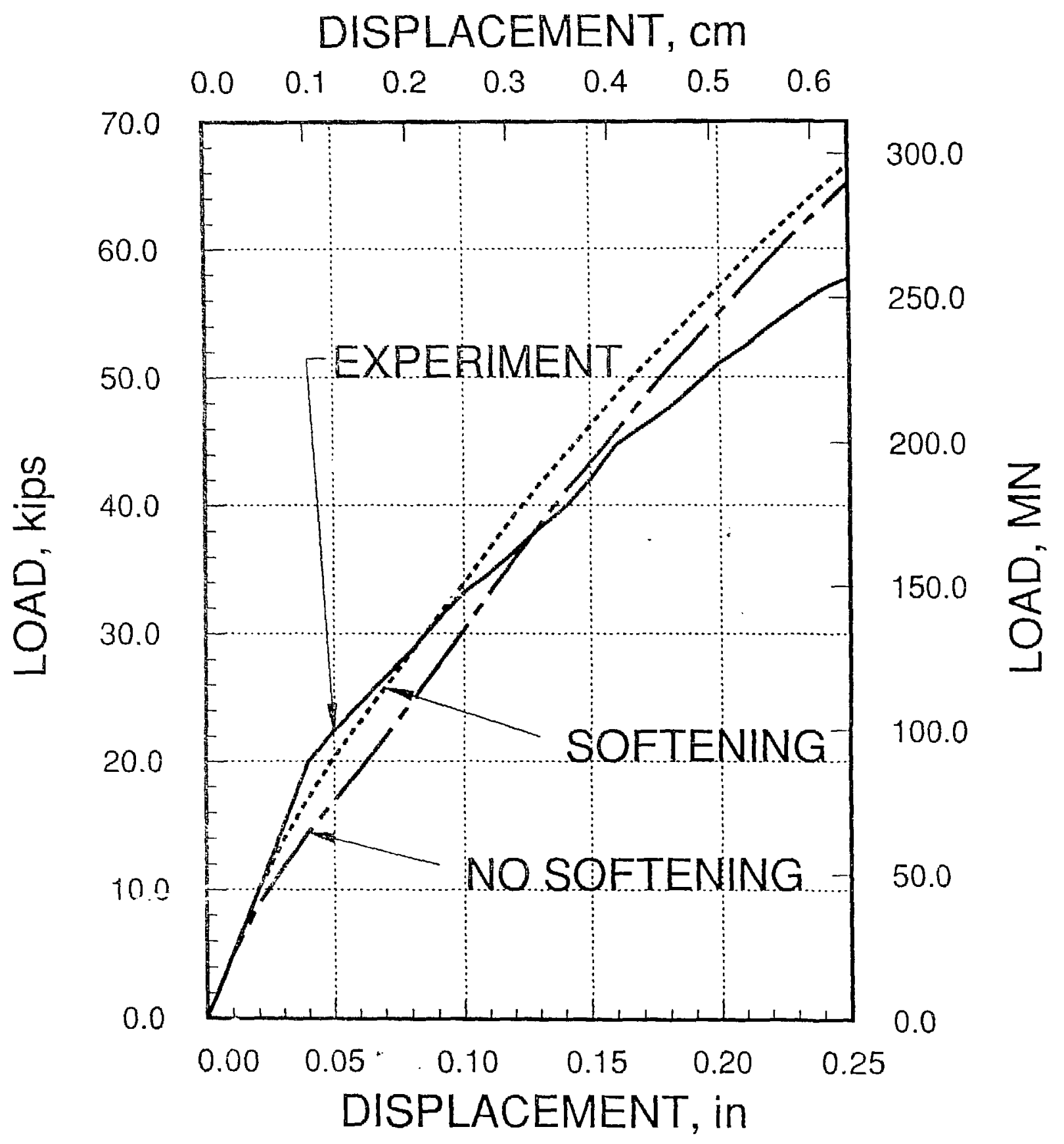

Figure 8. Load vs. Deflection for Beam Example 
certain cracking and debonding limitations in the analytical model. The agreement of test data and analytical results is quite good over the range for which the formulation was intended. The agreement with the rest data helps to validate the formulation of the reinforced beam element.

\subsection{One-Sixth Scale Axisymmetric Reinforced Concrete Containment Model}

The 1:6 scale reinforced concrete containment model shown in Fig. 9 has been constructed by Sandia National Laboratories [18]. The analysis of this model is considered for the following three different loading conditions: (1) static internal pressurization to failure with the complete structure at $70^{\circ} \mathrm{F}$ $\left(21^{\circ} \mathrm{C}\right),(2)$ static internal pressurization to failure with the structure at $400^{\circ} \mathrm{F}\left(204^{\circ} \mathrm{C}\right)$ internal1y and $70^{\circ} \mathrm{F}\left(21^{\circ} \mathrm{C}\right)$ externally (1inear variation thru the thickness), (3) dynamic threshold failure pressure subjected internally. Condition (1) is the loading at which the test will be conducted. Partial results are presented here for illustrative purposes. A complete set of results is given in the round-robin pretest failure prediction for the 1:6 scale containment model [19]. Loading conditions (2) and (3) are additional types of design/safety analyses of concrete containment structures which can be handled by TEMP-STRESS.

The finite element model shown in Fig. 10 consists only of the axisymmetric cylindrical vessel and a spherical dome. This model consists of 31 reinforced concrete shell elements: 12 of them representing the 7 in. (17.78 cm) thick spherical dome, one element representing the transition from the dome to the cylinder, and 18 elements representing the $93 / 4 \mathrm{in.}(24.77 \mathrm{~cm})$ thick cylinder. A liner on the inside surface of the vessel is made up of steel elements. The liner elements, which are offset from the concrete 


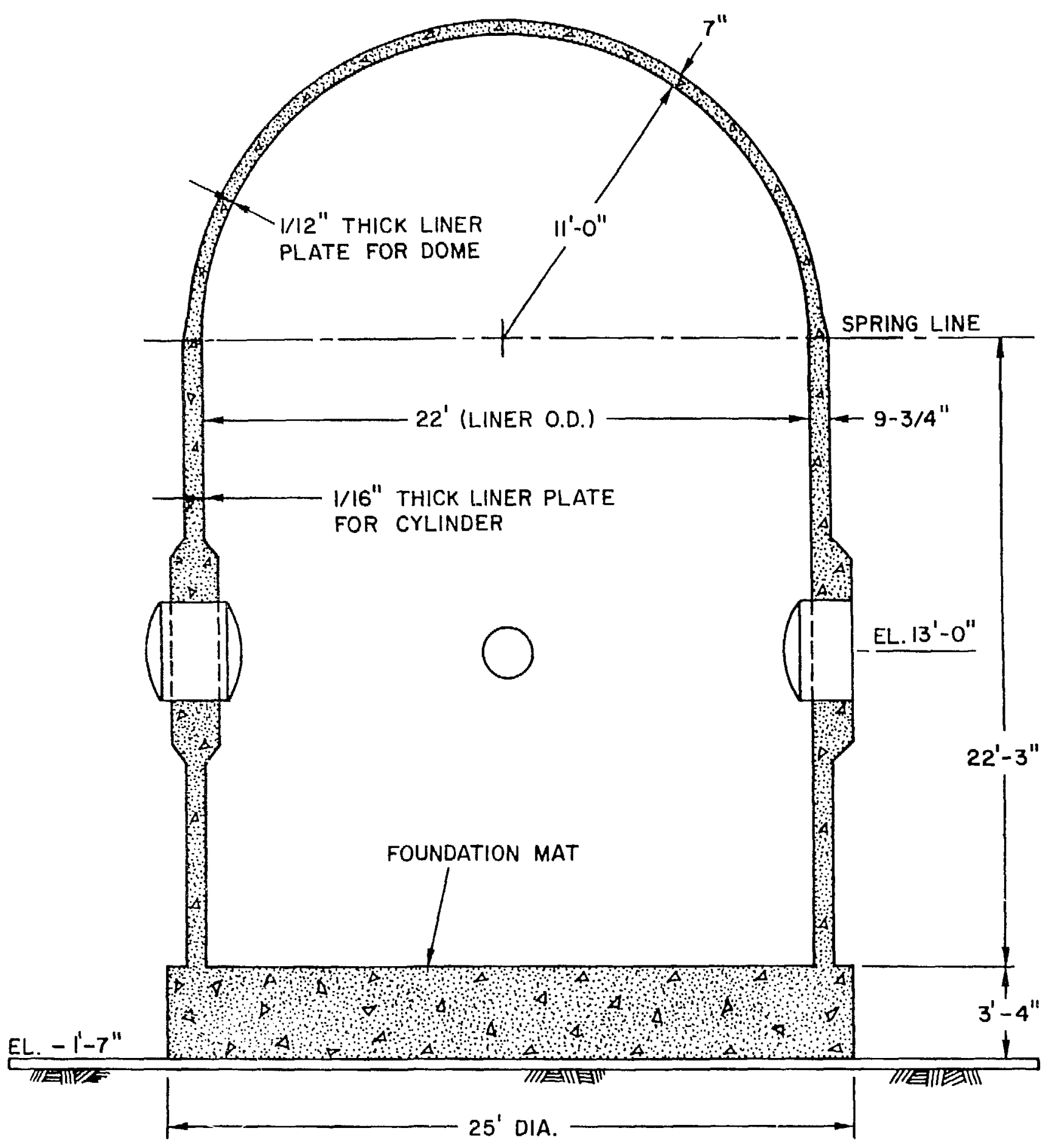

Figure 9. One-Sixth Scale Reinforced Concrete Containment 

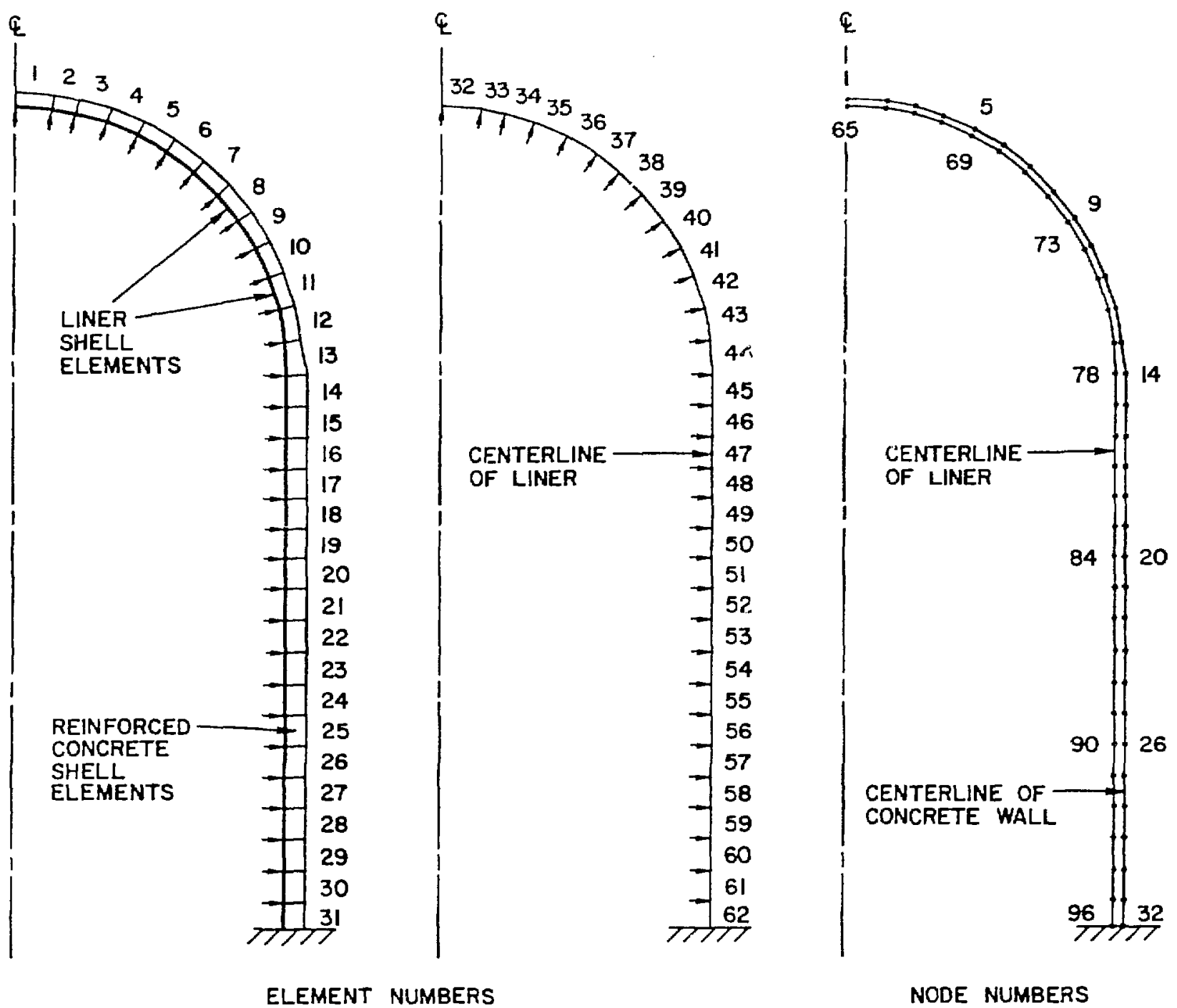

Figure 10. Discretization of Containment Mode] 
elements, have different thicknesses: $0.09 \mathrm{in.}(0.229 \mathrm{~cm})$ in the dome and $0.068 \mathrm{in} .(0.173 \mathrm{~cm})$ in the cylinder.

The number of reinforcement layers ranges from four in the spherical dome to 10 layers at the base of the cylinder. Fourteen different combinations of reinforcements are used with in the flexural elements.

Both steel and concrete are modeled as nonlinear materials. The constitutive equations for these materials are based on an elastic-plastic law with initial yielding and the subsequent loading surface described by the von Mises condition. An associated flow rule is used.

The strength capacity of the concrete in multiaxial stress space is characterized by the so-called Hsieh-Ting-Chen [20] four parameter failure surface. The concrete response after failure is simulated using the elementsize-independent cracking criterion established by Bazant and Oh [21]. In the uniaxial stress-strain relationship, a linear reduction of strength is specified from the ultimate stress down to zero. The maximum strain in tension (where the stress is specified as zero) for the solutions described in this example is $0.0007 \mathrm{in.} / \mathrm{in}$.

The properties of the concrete are: Young's modulus $=4800 \mathrm{ksi}(33100$ $\mathrm{MPa})$, Poisson's ratio $=0.2$, compression strength $=6800 \mathrm{psi}(46.9 \mathrm{MPa})$ and tensile strength $=500 \mathrm{psi}(3.45 \mathrm{MPa})$. Properties of the rebar are: Young's modulus $=31000 \mathrm{ksi}(214000 \mathrm{MPa})$, Poisson's ratio $=0.3$, yield stress $=66.6$ ksi (459 MPa) and ultimate stress $=99 \mathrm{ksi}(683 \mathrm{MPa})$ at $4.62 \%$ strain. Also, the liner properties are: Young's modulus $=30000 \mathrm{ksi}(207000 \mathrm{MPa})$, Poisson's ratio $=0.3$, yield stress $=50.2 \mathrm{ksi}(346 \mathrm{MPa})$ and ultimate stress $=70 \mathrm{ksi}$ (483 MPa) at $16.4 \%$ strain.

The thermal expansion of the concrete [22] is given by 


$$
\begin{aligned}
& \alpha=5.5 \times 10^{-6} / 0 \mathrm{~F} \text { for } \mathrm{T} \leq 300^{\circ} \mathrm{F}\left(1490^{\circ} \mathrm{C}\right) \\
& \alpha=(5.5+0.0042(T-300)) \times 10^{-6} / 0 \mathrm{~F} \text { for } \mathrm{T}>3000 \mathrm{~F}\left(149^{\circ} \mathrm{C}\right)
\end{aligned}
$$

The stress-strain behavior for concrete does not change appreciably from $70^{\circ} \mathrm{F}$ $\left(21^{\circ} \mathrm{C}\right)$ up to $400^{\circ} \mathrm{F}\left(204^{\circ} \mathrm{C}\right)$. So, as a simplification, the same stress-strain behavior was assumed for concrete from $70^{\circ} \mathrm{F}\left(21^{\circ} \mathrm{C}\right)$ to $400^{\circ} \mathrm{F}\left(204^{\circ} \mathrm{C}\right)$. The thermal expansion expression for steel |22| is

$$
\begin{aligned}
& \alpha=6.2 \times 10^{-6} / 0 \mathrm{~F} \text { for } T \leq 1000 \mathrm{~F}\left(38^{\circ} \mathrm{C}\right) \\
& \alpha=(6.0+0.002 \mathrm{~T}) \times 10^{-6} / 0 \mathrm{~F} \text { for } \mathrm{T}>1000 \mathrm{~F}\left(38^{\circ} \mathrm{C}\right)
\end{aligned}
$$

The stress-strain behavior for steel (rebar and liner) [22] at $400^{\circ} \mathrm{F}\left(204^{\circ} \mathrm{C}\right.$ ) is assumed to have the same strain with the stress values reduced to $83 \%$ from the values at $70^{\circ} \mathrm{F}\left(21^{\circ} \mathrm{C}\right)$. Therefore, the modulus of elasticity is also reduced to $83 \%$ from the $70^{\circ} \mathrm{F}\left(21^{\circ} \mathrm{C}\right)$ value. For temperatures between $70^{\circ} \mathrm{F}\left(21^{\circ} \mathrm{C}\right)$ and $400^{\circ} \mathrm{F}\left(204^{\circ} \mathrm{C}\right)$, a linear interpolation is used to describe the stressstrain behavior.

\subsubsection{Static Internal Pressurization}

For the static internal loading condition with uniform wa11 temperature, pressurization of the shell model is imposed by monotonically increasing the internal loading in $5 \mathrm{psig}(0.0345 \mathrm{MPa})$ increments. It is observed that up to 25 psig $(0.172 \mathrm{MPa})$ the behavior of the vessel is entirely elastic. At 
internal pressures $25-40$ psig $(0.172-0.276 \mathrm{MPa})$ meridional cracking at the base of the vessel propagates from the inside of the vessel to the neutral surface. The onset of hoop and meridional cracking in the cylinder above 40 psig $(0.276 \mathrm{MPa})$ is followed by hoop and meridional cracking in the dome. Hoop cracking and meridional cracking is practically completed at 90 psig (0.621 MPa) and $115 \mathrm{psig}(0.793 \mathrm{MPa})$, respectively.

Yielding of the liner is observed to start at about 100 psig ( 0.689 MPa) at mid-cylinder height, propagates along the cylinder and finally reaches the base at about $105 \mathrm{psig}(0.724 \mathrm{MPa})$. The yielding of hoop reinforcement on the inside of the concrete vesse 1 begins at about 120-125 psig (0.827-0.862 MPa). Failure of hoop reinforcement is governed by its strength; this stress $1 \mathrm{imit}$ of $99 \mathrm{ksi}(683 \mathrm{MPa}$ ) is reached at an internal pressure of about $185-190 \mathrm{psig}$ $(1.276-1.310 \mathrm{MPa})$. Failure of the hoop reinforcement is found to cause sudden failure of the liner and rupture. The deformed configuration of the vesse?, before impending failure, is shown in Fig. 11.

Deformation of the vessel, as well as the strains in the liner and the rebars are obtained for internal pressures ranging from 5 psig (0.0345 MPa) up to $185 \mathrm{psig}(1.276 \mathrm{MPa})$. Maximum vertical displacement at the dome apex before impending failure of the hoop rebar is $2.2 \mathrm{in}$. $(5.6 \mathrm{~cm})$, the corresponding vertical and radial displacements at the vessel springline are 2.6 in. $(6.6 \mathrm{~cm})$ and 2.4 in. $(6.1 \mathrm{~cm})$. The maximum radial and vertical displacements at cylinder midheight at this load are 5.7 in. $(14.5 \mathrm{~cm})$ and $0.9 \mathrm{in}$. $(2.3=\pi j)$, inenectively, while the respective hoop strain in the liner is 0.044 in./in. The displacements over the complete pressure loading at the cylinder midheight and vessel springline are given in Figs. 12 and 13, respectively. 


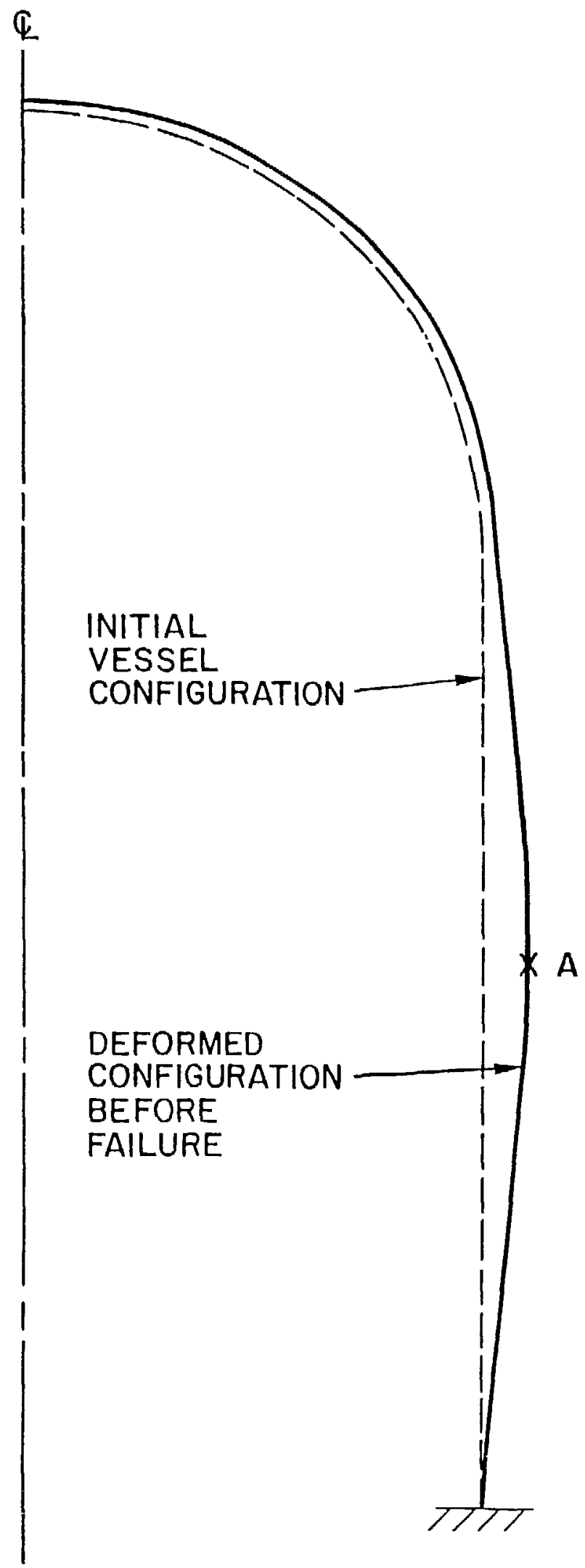

Figure 11. Deformation of Vessel at Impending Failure 


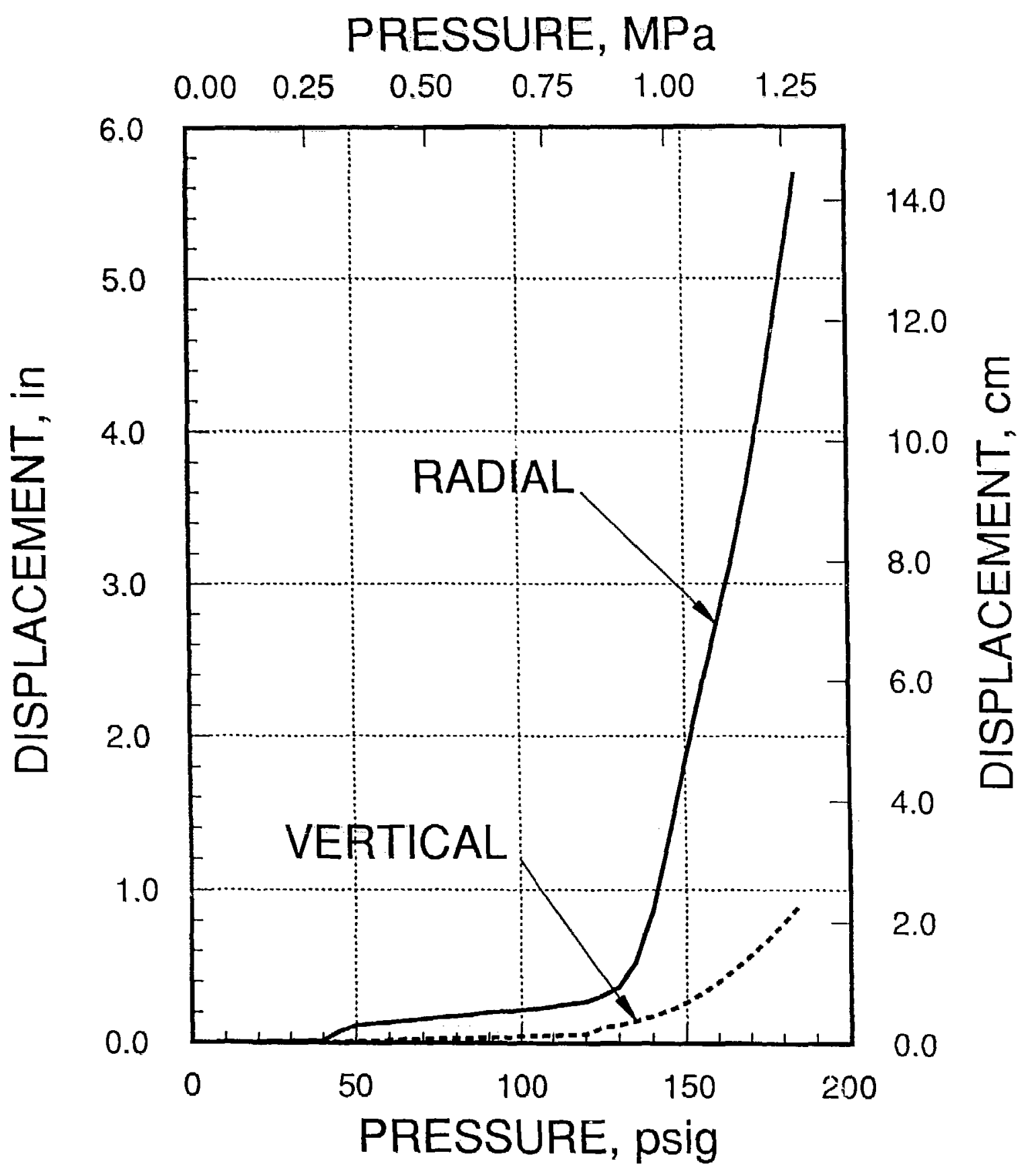

Figure 12. Radial and Vertical Displacements of Liner at Cylinder Midheight 


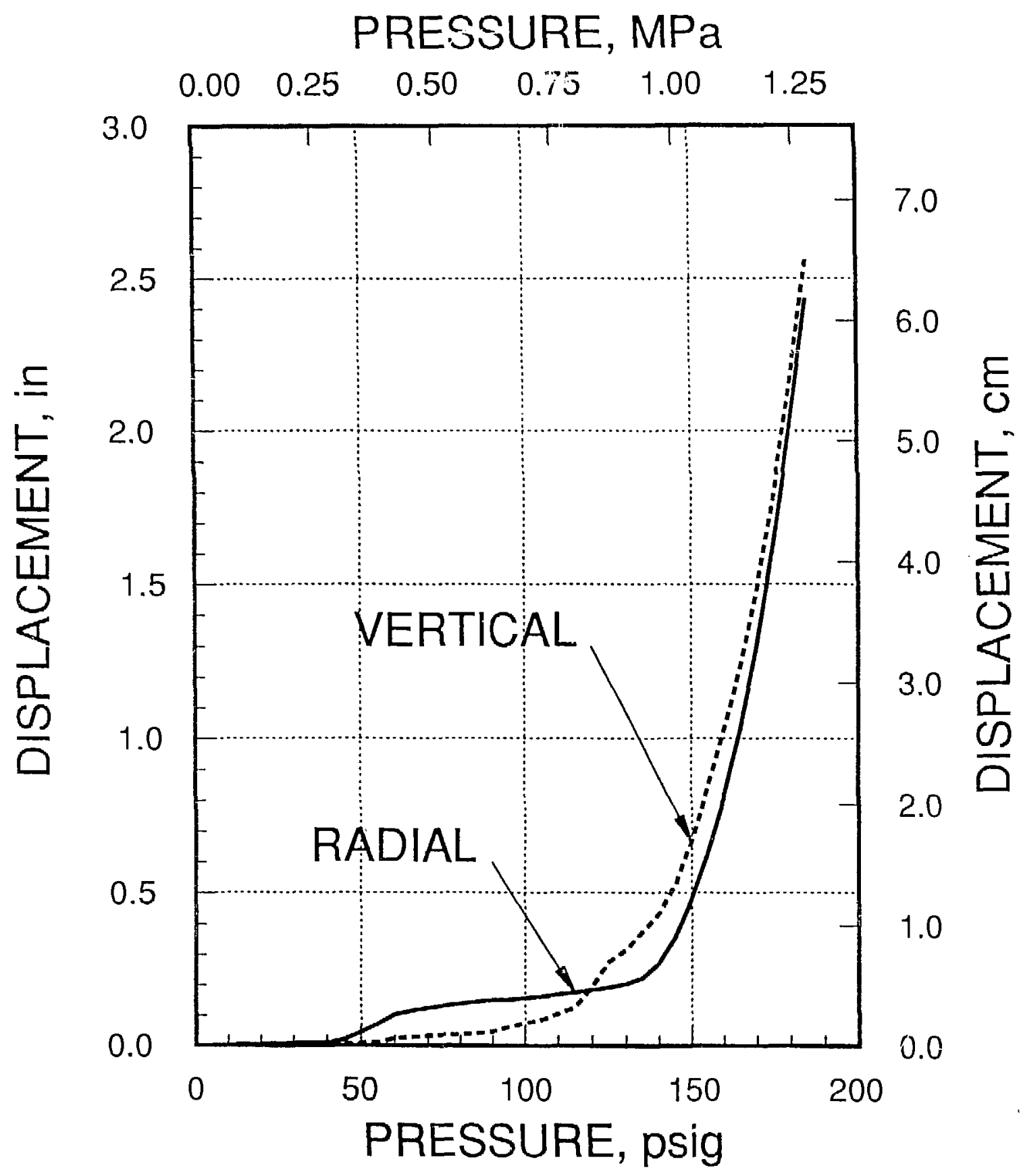

Figure 13. Radial and Vertical Displacements of Liner at Vessel Springline 


\subsubsection{Thermal Loading and Pressurization}

When the structure is subjected to elevated temperature as well as internal pressure, the loadings are performed sequentially. First, the thermal load is applied in $30^{\circ} \mathrm{F}\left(17^{\circ} \mathrm{C}\right)$ increments on the inside surface of the vessel up to the maximum of $400^{\circ} \mathrm{F}\left(204^{\circ} \mathrm{C}\right)$; the external surface is held at $70^{\circ} \mathrm{F}$ $\left(21^{\circ} \mathrm{C}\right)$ with a linear temperature variation maintained through the thickness. The pressure then is applied in $5 \mathrm{psig}(0.0345 \mathrm{MPa})$ increments until failure is reached. Meridional and hoop cracking of the dome and cylinder is observed on the outer surface of the structure in the first thermal load step. As the thermal load is increased from $130-400^{\circ} \mathrm{F}\left(54-204^{\circ} \mathrm{C}\right)$, meridional and hoop cracking of the dome and cylinder spreads from the outer surface to about twothirds of the way through the wall. As the pressure is applied from 5-105 psig (0.0345-0.724 MPa), cracking continues in the dome and cylinder. At 120 psig $(0.827 \mathrm{MPa})$, all the concrete has fully cracked except at the basemat juncture; the concrete in this region is in compression. Yielding of the hoop reinforcemen: in the cylinder starts at 120-125 psig (0.827-0.862 MPa). The ultimate strength of the rebar located near the cylinder midheight is exceeded at a pressure of $165-170$ psig (1.138-1.172 MPa). This leads to subsequent failure of the liner.

The deformations of the structure are similar to the non-thermal case; there is a 10-20\% increase in magnitude because of thermal softening effect on the material properties. The maximum vertica? displacement of the dome at impending failure in $2.6 \mathrm{in.}(6.6 \mathrm{~cm})$. The maximum springline radial and vertical displacements are $2.7 \mathrm{in} .(6.9 \mathrm{~cm})$ and $2.9 \mathrm{in} .(7.4 \mathrm{~cm})$, respective1y. At the cylinder midheight, $5.9 \mathrm{ir.} .(15.0 \mathrm{~cm})$ of radial displacement and $1.0 \mathrm{in.}(2.5 \mathrm{~cm})$ of vertical displacement were calculated. The maximum (hoop) liner strain at the midheight was 0.054 in./in. 


\subsubsection{Dynamic Loading}

The dynamic threshold failure pressure is found by internally loading the structure over a range of step load pressures. The maximum step pressure load that this vessel could withstand before impending failure was 150 psi (1.034 MPa). A time step of 20 us was employed to ensure stability for this loading. The failure for this loading was of the same mode and in the same general location as that given by the static pressure loading, hoop reinforcement failure followed by liner rupture near the cylinder midheight. In general, the displacement field is similar to the static response except at the springline. The maximum vertical displacement of the dome apex at this threshold failure pressure is $2.5 \mathrm{in} .(6.4 \mathrm{~cm})$ which took $40.8 \mathrm{~ms}$ to achieve. At the springline, the maximum radial displacement is $1.5 \mathrm{in}$. (3.8 $\mathrm{cm}$ ) at 32.8 ms while the maximum vertical displacement is $2.6 \mathrm{in} .(6.6 \mathrm{~cm})$ in $44.2 \mathrm{~ms}$. The corresponding radial and vertical displacemnnts at the cylinder midheight are 5.0 in. $(12.7 \mathrm{~cm})$ and $0.9 \mathrm{in} .(2.3 \mathrm{~cm})$ which were reached at $38.6 \mathrm{~ms}$ and $44.6 \mathrm{~ms}$, respectively. 


\section{CONCLUSIONS}

The TEMP-STRESS program reflects the present state of the art of concrete structural analysis. With the addition of these reinforced concrete flexure elements described in this paper, the program is suitable to treat a large variety of 2-D and axisymmetric 3-D problems. Its extended range of applicability has been demonstrated by several solutions involving different types of loads and material representations. TEMP-STRESS treats static and transient mechanical loads, as well as a variety of thermal loads. The nonlinear behavior of concrete is handled by the different constitutive models. These models include the tensile and compressive softening observed during tests of such materials. Many other special features for the treatment of concrete structures, are also available in the program.

The versatility of the TEMP-STRESS program is illustrated by the example solutions of this paper. On the one hand, a containment structure is subjected to a gradual internal pressurization (essentially static) and the history of response is obtained. The initiation of concrete cracking plus its location and direction can be observed. Subsequent yielding and rupture of the reinforcement and liner is also provided by the computer program. On the ather hand, the propagation of failure is also modeled by the computer program as the containment is subjected to an impulsive loading. The simulation of this response is followed in the same way as before: the pertinent areas of failure in concrete and the reinforcement are obtained. Thus, the structure can be subjected to any type of prescribed input loading which may need to be considered in the safety evaluations of the containment structure.

The TEMP-STRESS program also possesses a solid basis for analysis of structures under thermal environment. The program is equipped to handle 
thermal conduction problems with surface heat flux, surface convection and internal heat generation. Hence, at successive increments of time (or load) the concrete temperature is calculated by conduction; the thermal strains and corresponding stresses are then determined from the strutture's thermal state. This capability enables the program to determine the stress 'under the combined mechanical and thermal loading.

The thermal sample solution described assumed a linear steady state temperature field through the containment wall. This imposition of thermil loads $\left(400^{\circ} \mathrm{F}-70^{\circ} \mathrm{F}\right)$ through the walls of the. containment did not alter the failure pressure appreciably as compared to the solution of the problem without the temperature gradient. This occurred because the two main factors are compensating; thermal loads impose compressive stresses on the inside of the containment, while higher temperatures lower the ultimate reinforcing stresses. It is believed that at even higher temperature variations through the containment walls, the results could be appreciably different. This conclusion is based on the rather drastic strength reduction of both concrete and the reinforcing bars above $400^{\circ} \mathrm{F}[22]$.

The thermomechanical versatility of the TEMP-STRESS program can be extended even further by the incorporation of additional analytical models of phenomena which become important in concrete containment structures at very high temperatures. It has been observed that the containment capability at very high temperatures can be adversely affected by several important factors; namely: 1) the loss of bonding of reinforcement to concrete, which at a certain stage could be lost altogether, 2) the pore pressure within the concrete, and 3) surface spalling, for which the criterion of initiation is still unresolved. The significance of the phenomena must be investigated and resolved with appropriate analytical models supplemented by extensive experimental data. 


\section{ACKNOWLEDGEMENT}

This work was performed under the auspices of the U. S. Department of Energy, Office of Technology Support Program, under contract W-31-109-Eng-38. 


\section{REFERENCES}

[1] A. H. Marchertas, S. H. Fistedis, Z. P. Bazant and T. B. Belytschko, "Analysis and Application of Prestressed Concrete Reactor Vessels for LMFBR Containment," Nuclear Engineering and Design, 49(1,2) (1978) pp. 155-173.

[2] A. H. Marchertas and T.B. Belytschko, "Transient Analysis of a PCRV for LMFBR Primary Containments," Nuclear Technology, 51(3) (1980) pp. 433442 .

[3] A. H. Marchertas, "DYNAPCON: A Computer Code for DYNamic Analysis of Prestressed CoNcrete Structures," Argonne National Laboratory Report, ANL-82-77 (September 1982).

[4] R. W. Seidensticker, A. H. Marchertas and Z. P. Bazant, "Increasing Primary Containment Capabilities of Liquid-Metal Fast Breeder Reactor Plants by the Use of Prestressed Concrete," Nuclear Technology, 51(3) (1980) pp. 443-451.

[5] A. H. Marchertas and R. F. Kulak, "Numerical Modeling of Concrete Under Thermal Loads," Nuclear Engineering and Design, 68(2) (1981) pp. 225-236.

[6] A. H. Marchertas and R. F. Kulak, "A Coupled Heat Conduction and Thermal Stress Formulation Using Explicit Integration," Arqorine National Laboratory Report, ANL-82-47 (June 1982).

[7] A. H. Marchertas and R. F. Kulak, "Response Simulation of Concrete Structures to High Temperatures," Proceedings of the Workshop on Containment Integrity, Vol. 1, NUREG/CP-0033, SAND82-1659, Sandia National Laboratories (1982) pp. 193-212.

[8] Y. Takahashi, "Elastic-Plastic Constitutive Modeling of Concrete," Argonne National Laboratory Report, ANL-83-23 (March 1983).

[9] A. H. Marchertas, "Thermo-Mechanical Analysis of Concrete in LMFBR Programs," Nuclear Engineering and Design, 82(1) (1984) pp. 47-62.

[10] J. M. Kennedy, "Nonlinear Dynanic Response to Reactor-Core Subassemblies," Argonne National Laboratory Report, ANL-8065 (January 1974).

[11] D. F. Schoeberle, J. M. Kennedy, and T. B. Belytschko, "Implicit Temporal Integration for Long-Duration Accidents in a Structural Response Code-STRAW," Nuclear Engineering and Design, 49 (1978) pp. 39-50.

[12] R. F. Kulak, T. B. Belytschko, J. M. Kennedy, and D. F. Schoeberle, "Finite Element Formulation for Thermal Stress Analysis of Thin Reactor Structures," Nuclear Engineering and Design, 49 (1978) pp. 39-50.

[13] H. L. Schreyer, J. M. Kennedy, and D. F. Schoeberle, "Thermoviscoplastic Analysis of First Walls Subjected to Fusion Power Transients," Journal of Pressure Vessel Technology, 105 (1983) pp. 42-51. 
[14] T. B. Belytschko and B. J. Hsieh, "Nonlinear Transient Finite Element Analysis with Convected Coordinates," International Journal for Numerical Methods in Engineering, 7 (1973) pp. 255-271.

[15] T. B. Belytschko and B. J. Hsieh, "Nonlinear Transient Analys is of Shells and Solids of Revolution by Convected Elements," AIAA Journal, 12 (1974) pp. 1031-1035.

[16] A. H. Marchertas and R. F. Kulak, "Numerical Modeling of Concrete Under Thermal Loads," Nuclear Engineering and Design, 63(2) (1981) pp. 225236.

[17] P. G. Underwood, "An Adaptive Dynamic Relaxation Technique for Nonlinear Structural Analysis," Lockheed Palo Alto Research Laboratory Report, LMSCD678265 (1979).

1181 D. S. Horschel and J. Jung, "Construction and Analys is of a 1/6th-scale Concrete Containment Model," Proceedings of the Third Workshop on Containment Integrity, NUREG/CP-0076, SAND86-0618, Sandia National Laboratories (1986) pp. 407-428.

[19] D. B. Clauss, editor, "Round-Robin Pretest Analyses of a 1:6-scale Reinforced Concrete Containment Model Subject to Static Internal Pressurization," NUREG/CR-4913, SAND87-0841, Sandia National Laboratories (1987) pp. 82-129.

(20) S. S. Hsieh, E. C. Ting, and W. F. Chen, "A Plastic-Fracture Model for Concrete," International Journal of Solids and Structures, 18(3) (1982) pp. 181-197.

[21] 2. P. Bazant and B. H. Oh, "Crack Band Theory for Fracture of Concrete," Materiaux et Constructions, 16(93) pp. 155-177.

122] G. N. Freskakis, private communication (1985). 